\title{
ARTÍCULOS
}

\section{NUEVOS DATOS DE ETNOARQUEOLOGÍA ZOOARQUEOLÓGICA DESDE EL OESTE DE GROENLANDIA.}

\author{
Santiago David Domínguez Solera \\ ARES Arqueología y Patrimonio Cultural \\ cazadorrecolector@hotmail.com
}

Resumen: Este trabajo presenta una serie de datos obtenidos en el verano de 2017 sobre la caza y el procesado del caribú (Rangifer tarandus) y de la foca (Phocidae) y la pesca del bacalao (Gadus morhua) en el área de Sisimiut (oeste de Groenlandia), por parte de cazadores y pescadores inuit. La información se recabó mediante entrevistas, observación directa de las actividades de caza y pesca, prospecciones y análisis tafonómicos de los restos óseos. Se constata el mantenimiento de conceptos tradicionales de caza, carnicería, transporte, reparto y consumo aún presentes entre los actuales groenlandeses y usos culturales diferentes entre áreas relativamente próximas.

Palabras clave: Inuit, Oeste de Groenlandia, Zooarqueología, Etnoarqueología.

Tittle: NEW DATA ON ZOOARCHAEOLOGICAL ETHNOARCHAEOLOGY FROM WESTERN GREENLAND.

Abstract: The present work contains several data obtained in the summer of 2017 about the hunting and processing of caribou (Rangifer tarandus) and seals (Phocidae) and the fishing of cod (Gadus morhua) in the Sisimiut area (West Greenland) by Inuit hunters and fishers. Data were collected through interviews, direct observation of hunting and fishing activities, prospecting and taphonomic analysis of the skeletal remains. The maintenance of traditional concepts of hunting, butchery, transport, distribution and consumption are still present among current Greenlanders. Different cultural uses between relatively close areas are demonstrated.

Keywords: Inuit, West Greenland, Zooarchaeology, Ethnoarchaelogy.

\section{Introducción}

En el inicio de una línea de investigación dedicada a la recopilación de información etnográfica de interés para la Zooarqueología se viajó en el verano de 2012 al oeste de Groenlandia para la elaboración de la tesis doctoral del autor de

Cómo citar este artículo: DOMÍNGUEZ SOLERA, Santiago David. Nuevos datos de Etnoarqueología Zooarqueológica desde el oeste de Groenlandia. Naveg@mérica. Revista electrónica editada por la Asociación Española de Americanistas [en línea]. 2020, n. 25. Disponible en: <http://revistas.um.es/navegamerica>. [Consulta: Fecha de consulta]. ISSN 1989-211X. 
este artículo ${ }^{1}$ y para el rodaje de una serie documental para televisión. Se obtuvieron datos principalmente sobre la caza del caribú y de otros animales terrestres y marinos así como información etnográfica y arqueológica. Todos los datos obtenidos entonces ya han sido convenientemente publicados ${ }^{2}$. En el verano de 2017 el aquí firmante retornó al oeste de Groenlandia para filmar un nuevo documental junto con el operador de cámara Dorian Sanz, obteniendo los datos que aquí se presentan ${ }^{3}$.

Estos trabajos se circunscriben dentro de un proyecto de investigación mayor y que pretende la recogida directa de información sobre caza y procesado animal entre comunidades actuales de tradición cazadora-recolectora y de distintos contextos geográficos-climáticos (además de con los Inuit de Groenlandia se ha trabajado con los Ayoreo de la selva del Chaco Paraguayo y con los Ju/'hoansi del Kalahari de Namibia). Su objetivo principal es la documentación de diferencias y pautas comunes a la hora del tratamiento de los restos animales, teniendo en cuenta la influencia en las cadenas operativas tanto de aspectos funcionalistas como de carácter simbólico e identitario. Se presta especial atención al resultado material de las actividades cinegéticas para obtener conclusiones útiles a la hora de interpretar el registro arqueológico de comunidades forrajeadoras extintas (Etnoarqueología ${ }^{4}$ ).

Puesto que caza y pesca siguen siendo realidades económicas y culturales esenciales para los habitantes del oeste de Groenlandia, en 2017 se desarrolló una segunda campaña "zoo-etnoarqueológica" allí para ampliar, complementar y reforzar la información previamente obtenida. Así se obtuvieron nuevos datos sobre la caza del caribú (Rangifer tarandus) y sobre la pesca del bacalao (Gadus morhua), pero también sobre la caza y procesado de especies apenas trabajadas en la campaña precedente y en la bibliografía análoga, tales como focas (Phocidae) y buey almizclero (Ovibos moschatus). También se pretendían constatar más pervivencias

\footnotetext{
${ }^{1}$ DOMÍNGUEZ-SOLERA, S. D. Estudio etnoarqueológico: cadenas operativas de caza y procesado animal entre grupos cazadores-recolectores [tesis doctoral]. Madrid: Universidad Complutense de Madrid, 2017.

${ }_{2}$ DOMÍNGUEZ-SOLERA, S. D. Rituales de paso de los cazadores españoles actuales (Estudio etnoarqueológico). Arqueoweb. Revista sobre Arqueología en Internet. 2008, vol. 9, n. 2; DOMÍNGUEZ-SOLERA, S. D. With only one Flake. An Experiment about the Posibilities Processing a Carcass with Flint during Hunting. Journal of Taphonomy. 2012, vol. 10, n. 2, pp. 113-121; DOMÍNGUEZ-SOLERA, S. D. Los Inuit. Caza y pesca en el Oeste de Groenlandia. Cuaderno de Campo. Madrid: Libros Clan, 2014; DOMíNGUEZ-SOLERA, S. D. Inuksuit en el oeste de Groenlandia: símbolo y huella de la relación ancestral de los inuit con el espacio. Revista Española de Antropología Americana. 2014, vol. 44, n. 1, pp. 151-166; DOMÍNGUEZ-SOLERA, S. D. Etnoarqueología y el mar en el Oeste de Groenlandia: varios apuntes útiles sobre la pesca del bacalao. En: HOCES-GARCÍA, A. y MORAL-GARCÍA, C. (coords.). El mar: una forma de vida en América. Madrid: Historia y Cultura del Mar, 2016, pp. 243-272; DOMÍNGUEZ-SOLERA, S. D. Por tierra y por mar: reflexiones sobre la caza en el Oeste de Groenlandia. Naveg@mérica, Revista electrónica editada por la Asociación Española de Americanistas. 2017, n. 18.

${ }^{3}$ Gracias en primer lugar a los/las informantes mencionados/as en el texto por abrirnos las puertas de sus casas y embarcaciones y por cedernos altruistamente su tiempo y conocimientos. También a mi compañero de aventuras internacionales, el cámara Dorian Sanz (DOJO Producciones). En segundo lugar, gracias a la profesora Emma Sánchez Montañés por animarme a aprender de las comunidades indígenas americanas y por corregir el presente manuscrito. Gracias, en última instancia, al Ayuntamiento de Cuenca (España) por financiar la producción del documental que sirvió de excusa e infraestructura para esta campaña de investigación.

${ }^{4}$ GONZÁLEZ-RUIBAL, A. La experiencia del otro. Una introducción a la Etnoarqueoligía. Madrid: Akal, 2003.
} 
propias y definitorias de la mentalidad cazadora-recolectora heredadas en los hábitos cinegéticos de los actuales inuit groenlandeses. Por último, se buscaba ampliar el inventario de subzonas visitadas para incidir sobre la idea de que la variabilidad del repertorio técnico del procesado animal, motivada por cuestiones educacionales y culturales, puede ser perceptible incluso entre colectivos inmediatos y pertenecientes a una misma etnia, aun ocupando un idéntico escenario geográfico y disponiendo de unos mismos recursos faunísticos. Por ello, en la campaña de 2012 se convivió con familias inuit de Nuuk, Kapisillit y Atammik y en la de 2017 se visitaron las zonas de Kangerslussuaq, Sisimiut, Sarrfanguaq e Itilleq, unos 200 kilómetros más al norte del área previamente estudiada (Fig. 1). 

oeste de Groenlandia.
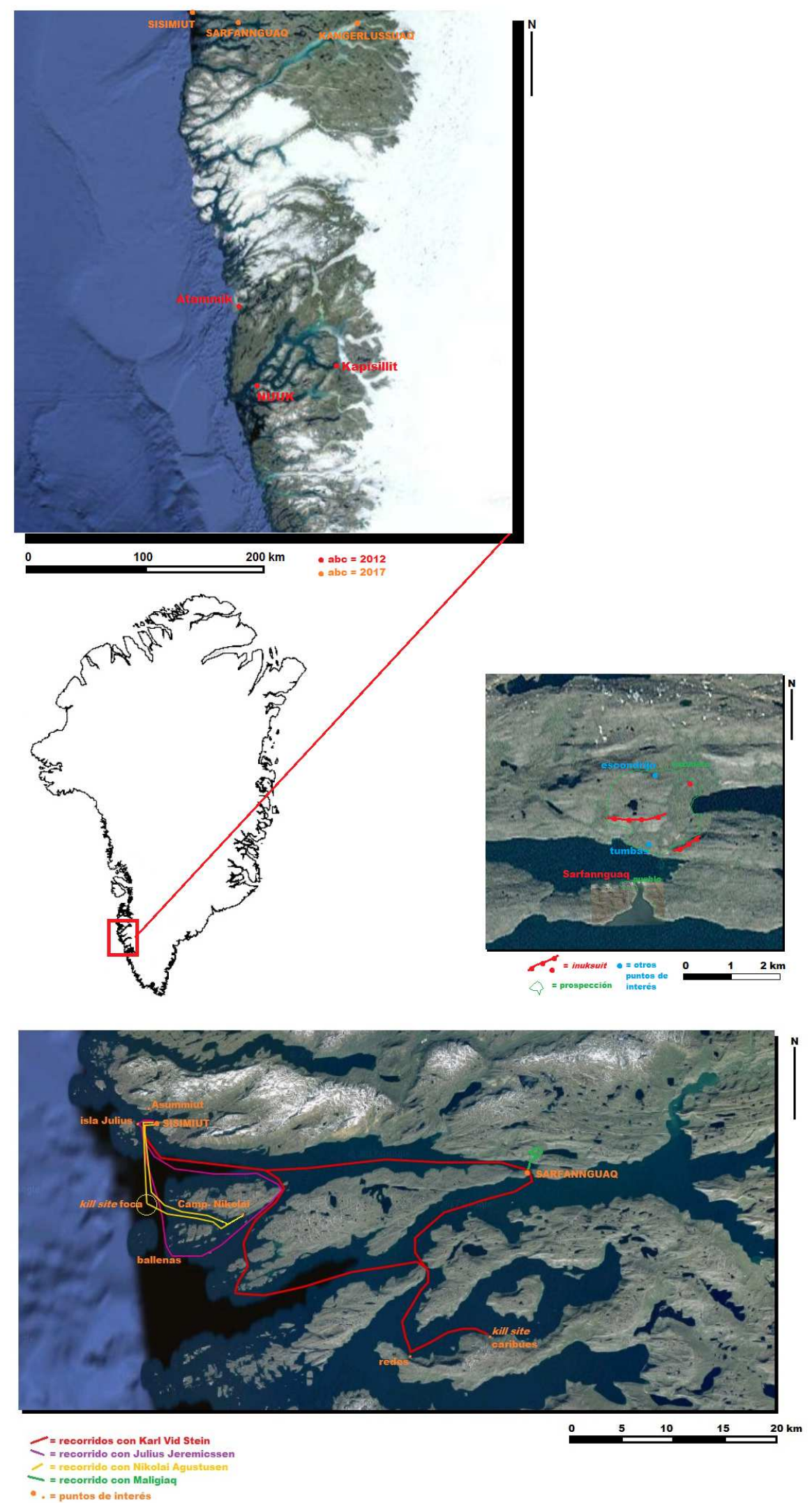

Fig. 1: Área de estudio: detalle de los alrededores de Sisimiut y de Sarfannguaq con la zona de caza prospectada. Fuente: Lámina del autor sobre capturas del visor Google Earth. 


\section{Método}

Se abordaron diferentes poblaciones para establecer relación directa y convivir con el mayor número de personas que siguieran dedicadas a la caza y la pesca. Todas se prestaron voluntariamente y sin ningún tipo de incentivo económico a compartir su forma de vida cotidiana (permitiéndonos pernoctar incluso en sus barcos, refugios y casas). Se pudo observar así de forma más fidedigna el día de los informantes y tener acceso mucho más constante a obras y testimonios. La comunicación se desarrolló íntegramente en inglés, empleando ciertas expresiones clave en groenlandés. La traducción simultánea puntual de algunos vecinos de las aldeas permitió profundizar en el trato con personas que, pese a conocerlo, no dominaban ágilmente el inglés. Para conseguir una muestra de testimonios más amplia e ilustrativa sobre pervivencias y reinterpretaciones culturales, se trabajó tanto con informantes de ascendencia inuit juveniles, como adultos y ancianos, de ambos sexos.

El trabajo de campo se hizo coincidir conscientemente con el momento en el que se desarrolla con más intensidad en esta parte de Groenlandia -julio, agosto y septiembre- la caza del caribú y otras especies terrestres y marinas veraniegas.

Todas las acciones del trabajo de campo se diseñaron en pro de la documentación de la totalidad de la secuencia o cadena operativa que va desde la educación como cazadores y pescadores, pasa por el acto de la caza-pesca propiamente dicho, el procesado animal (carnicería), el consumo y llega hasta la deposición de los restos y todas las cuestiones sociales, culturales y económicas en ello concurrentes.

Las actividades de documentación consistieron en acompañar a los cazadores y a los pescadores, grabando en vídeo y dron, haciendo fotografías, cuantificando tiempos, realizando mediciones GPS, tomando anotaciones en campo y realizando dibujos y planimetrías. Los testimonios orales proceden tanto de conversaciones naturales y espontáneas como de baterías de preguntas preestablecidas sobre técnicas, decisiones, costumbres o significados.

Las expediciones de caza se aprovecharon como prospecciones extensivas para encontrar restos esqueléticos en campo. También se realizaron prospecciones intensivas en zonas de especial interés. Todos los restos esqueléticos detectados se inventariaron e identificaron taxonómicamente en campo y se analizaron tafonómicamente (marcas de corte, diente, etc. en sus superficies óseas ${ }^{5}$ ) mediante lupas portátiles.

También se visitaron museos, instituciones y centros de artesanía para completar información sobre formas de consumo y producción actuales en contraste con los usos más tradicionales.

\footnotetext{
5 YRAVEDRA SAINZ DE LOS TERREROS, J. Tafonomía aplicada a Zooarqueología. Madrid: Universidad Nacional de Educación a Distancia, 2006.
} 


\section{Resultados}

\subsection{Kangerlussuak}

El origen del pueblo actual son las bases aéreas estadounidenses que se ubicaron en la cabeza del fiordo del mismo nombre en el contexto de la II Guerra Mundial y que finalmente se convirtieron en un aeropuerto civil, con gran afluencia de turistas atraídos por la proximidad de un glaciar y por la importante oferta de paquetes deportivos y cinegéticos. En el pasado, tanto inuit como en el de todas las culturas paleoesquimales precedentes, era ya un punto de caza estival al que acudían familias y grupos desde los poblados de la costa para establecerse en campamentos como el representado en el yacimiento arqueológico inmediato de Aasivissuit ${ }^{6}$. La caza del caribú, tuttu en groenlandés, es desde hace milenios el recurso más importante en este punto del interior que sigue siendo el referente geográfico al que acuden muchas familias groenlandesas para cazarlo desde Sisimiut y desde otras ciudades costeras. La caza del buey almizclero es otro de los atractivos principales, tanto para turistas y cazadores deportivos como para los cazadores groenlandeses que aún confían en exclusiva o se apoyan en gran medida en la caza como forma de vida. Es una especie no oriunda de la zona aunque sí del Ártico, introducida a mediados del siglo $\mathrm{XX}^{7}$, por lo que su caza actual no tiene raigambre tradicional.

Según los informantes consultados ${ }^{8}-\mathrm{y}$ a diferencia del contexto conocido en Atammik y Kapisillit en 2012 y del que se describirá para Sisimiut y Sarfannguaq- en el pueblo/aeropuerto de Kangerlussuak viven apenas cuatro cazadores con dedicación exclusiva. Sólo uno de ellos (Amâsa Olsen) es de ascendencia inuit; los demás vecinos de esa etnia están empleados en el aeropuerto, en infraestructuras hoteleras, en tiendas de recuerdos y en los establecimientos de servicios turísticos, logísticos y de uso interno. Muchos también cazan, siguiendo la tradición familiar, pero no con dedicación plena, sino como afición y como complemento económico puntual. Los dos cazadores groenlandeses "profesionales" a los que entrevistamos, nos explicaron que no podían cazar en agosto y septiembre para sus propios fines, ya que diariamente están ocupados acompañando comercialmente a cazadores extranjeros. Este panorama es determinante para la correcta interpretación del registro faunístico observado en las zonas de caza y en el pueblo.

En primer lugar se prospectaron extensivamente los alrededores de Kangerlusuak, concretamente el área que separa la población por el NE del frente glaciar próximo, en busca de restos óseos, tanto producto de actividad cinegética

${ }^{6}$ GRøNNOW, B.; MELDGAARD, M. y NIELSEN, J. B. Aasivissuit - The Great Summer Camp. Archaeological, Ethnographical and Zoo-archaeological Studies of a Caribou-hunting Site in West Greenland. Meddelelser om Grønland. Copenhague: Danish Polar Center, 1983.

${ }^{7}$ SANDELL, H. T. Archaeology and Environment in the Scaresby Sund Fjord. Ethno-archaeological Investigations of the Last Thule Culture of Notheast Greenland. Meddelelser om Grønland, Man and Society. Copenhague: Danish Polar Center, 1991, pp. 115-116.

8 Ramón Laramendi, Sam ¿?, Thomas Rasmussen, Amâsa Olsen, Carsten Links, Eggent Gudmuussen, Fin Thomsen, Kalunnguaq Madsen, Jens Pavia, Marc ¿?, Jen Olsen, Adam Hansen, Monica Rask Kleist, Tommy Kanstrup, Jens Dahl, Minik Knudsen, Laila K. Thomassen, Johan Lange, Anthon Sommer y Nini F. Holstebro. 
humana como generados por procesos no antrópicos. Sólo se detectó un punto de acumulación ósea en la parte superior de un pequeño cerro: la carcasa parcial de un buey almizclero de apenas un año en el momento de la muerte, según los patrones de deterioro causados por la intemperie y por los procesos de congelación propios del Ártico. El inventario de restos se organiza en función de las tres agrupaciones secundarias en las que se dividía la carcasa:

1. Costilla.

2. Húmero derecho y ulna derecha.

3. Escápula derecha, escápula izquierda, columna vertebral completa, costillas (parcial) y carpales.

En todos los restos las alteraciones tafonómicas eran marcas de dientes de pequeños carnívoros y omnívoros. Por la falta de medios técnicos adecuados, no se pudieron realizar análisis de marcas de pico, producto de grandes aves carroñeras ${ }^{9}$. No se observaron marcas de corte, pero sí la huella de un disparo o perforación circular y la fractura asociada por el impacto de bala en una de las escápulas: el cazador habría apuntado al corazón de la presa buscando un impacto mortal. Destaca la ausencia de los cuartos traseros y de la cabeza. Se prospectó ampliamente la zona en busca de los elementos esqueléticos ausentes que habrían podido ser desplazados, escondidos o destruidos por pequeños carnívoros y carroñeros. En esta zona de Groenlandia ${ }^{10}$ los principales agentes animales carroñeros terrestres que inciden sobre las carcasas en tierra son los zorros (Alopex lagopus) y los cuervos (Corvus corax). Se interpretó el escenario como producto de un episodio de caza deportiva, en el que tras abatir al animal in situ y cobrarlo, ni se evisceró ni se desolló, llevándose sólo la cabeza como trofeo y apenas la mitad trasera para aprovechar la carne de las patas y la pelvis. La carne de las patas delanteras, habiéndose estropeado una de las mazas principales por el disparo y la de lomos, cuello y parte intermedia de las costillas, se despreció y descartó habiendo sido consumida y desplazada por zorros y cuervos. Los restos resecos quedaron a merced de los procesos de intemperie y congelación ${ }^{11}$.

El análisis general de los restos esqueléticos que llegan al pueblo y la entrevista a cazadores "profesionales" y aficionados, certifican que la mayoría de episodios de caza en la zona no son responsabilidad de groenlandeses, sino que priorizan la obtención de trofeos en el sentido occidental ${ }^{12}$ y apenas se transporta algo de carne. Cráneos de bueyes almizcleros se exhiben en los porches de las casas, en los tejados y en el interior de las viviendas, tanto por gente de ascendencia inuit como por extranjeros. En las calles del pueblo apenas se encuentran restos esqueléticos relacionados con trabajos de carnicería y sólo en el almacén y caseta de Amâsa

\footnotetext{
${ }^{9}$ DOMÍNGUEZ-SOLERA, S. D. y DOMÍNGUEZ-RODRIGO, M. A Taphonomic Study of a Carcass Consumed by Griffon Vultures (Gyps fulvus) and its Relevance for the Interpretation of Bone Surface Modifications. Journal of Archaeological and Anthropological Scieces. 2011, vol. 3, n. 4, pp. 385-392.

10 PASDA, K. Zur Taphonomie von Rentieren (Rangifer tarandus grienlandicus) in der Tundra Westgrönlands. Quartär. 2001, n. 51/52, pp. 173-194.

11 WOOD, W. R. y Johnson, D. L. A Survey of Disturbance Processes in Archaeological Site Formation. Advances in Archaeological Method and Theory. Nueva York: Academic Press, 1978, pp. 315-380.

${ }^{12}$ DOMÍNGUEZ-SOLERA, S. D. Rituales de paso... Op. cit.
} 
Olsen existen descartes de metápodos y huesos de bueyes almizcleros y caribúes de cierto interés (Fig. 2).
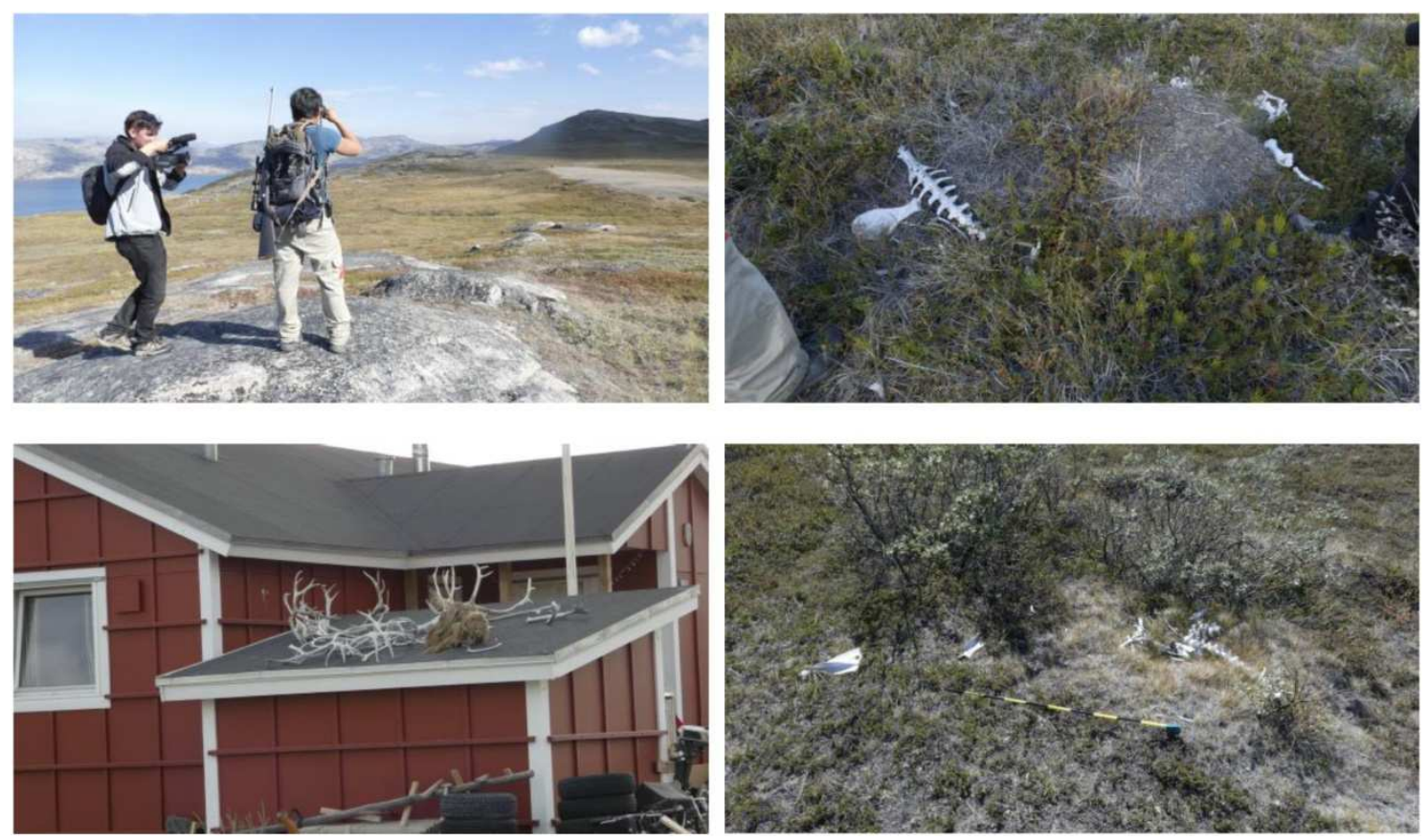

Fig. 2: Kangerlussuak. De arriba hacia abajo y de izquierda a derecha: zona de caza, carcasa completa de caribú sin cráneo; trofeos de Amâsa Olsen y carcasa casi completa de buey almizclero sin el cráneo. Fuente: Fotografías del autor.

El informante Minik Knudsen -estudiante de 19 años y cazador- nos llevó a una zona más adecuada para la caza del caribú, en el Lago Ferguson o Tasersuatsiaq y junto al Monte Ammalortup. Prospectamos extensivamente el cazadero, recogiendo restos para su estudio (Tabla 1). 


\begin{tabular}{|c|c|c|c|c|c|}
\hline \multicolumn{6}{|c|}{ Inventario de material faunístico documentado durante la prospección en Kangerlussuak en 2017} \\
\hline Resto/conjunto & Especie & Edad & Parte anatóm. & Alteraciones & Observaciones \\
\hline Falange intermedia & $\begin{array}{l}\text { Rangifer } \\
\text { tarandus }\end{array}$ & Juvenil & Apendicular & Weathering & Completa \\
\hline $\begin{array}{lr}\text { Conjunto } & \text { de } \\
\text { extremidad } & \text { trasera } \\
\text { derecha } & \end{array}$ & $\begin{array}{l}\text { Rangifer } \\
\text { tarandus }\end{array}$ & Adulta & Apendicular & $\begin{array}{l}\text { Marcas de diente de } \\
\text { mordisqueo con } \\
\text { extracción de tejido en } \\
\text { ep. distal y proximal del } \\
\text { fémur, parte proximal de } \\
\text { la tibia } \\
\text { Marcas de diente más } \\
\text { leves en el resto de } \\
\text { elementos }\end{array}$ & $\begin{array}{l}\text { Completa y articulada } \\
\text { (falanges, metatarso, tarso } \\
\text { y tibia en articulación + } \\
\text { fémur desarticulado) }\end{array}$ \\
\hline Fémur & $\begin{array}{l}\text { Rangifer } \\
\text { tarandus }\end{array}$ & Adulto & Apendicular & $\begin{array}{l}\text { Weathering } \\
\text { Diente en ep. proximal y } \\
\text { distal }\end{array}$ & Completo \\
\hline Fémur derecho & $\begin{array}{l}\text { Rangifer } \\
\text { tarandus }\end{array}$ & Adulto & Apendicular & $\begin{array}{l}\text { Marcas de diente poco } \\
\text { conspicuas en ep. y } \\
\text { diáfisis }\end{array}$ & Completo \\
\hline Cráneo & $\begin{array}{l}\text { Rangifer } \\
\text { tarandus }\end{array}$ & Adulto & Craneal & & Completo, hembra \\
\hline $\begin{array}{ll}4 & \text { vértebras } \\
\text { lumbares }\end{array}$ & $\begin{array}{l}\text { Rangifer } \\
\text { tarandus }\end{array}$ & Infantil/juvenil & Axial & Marcas de diente & Completas \\
\hline $\begin{array}{ll}\text { Conjunto } & \text { de } \\
\text { extremidad } & \\
\text { delantera } & \\
\end{array}$ & $\begin{array}{l}\text { Rangifer } \\
\text { tarandus }\end{array}$ & Adulta & Apendicular & $\begin{array}{l}\text { Marcas de weathering } \\
\text { Marcas de raíces }\end{array}$ & $\begin{array}{l}\text { Completas las piezas } \\
\text { (metacarpo y } 2 \text { piezas del } \\
\text { carpo) y articuladas }\end{array}$ \\
\hline Carcasa parcial & $\begin{array}{l}\text { Rangifer } \\
\text { tarandus }\end{array}$ & Adulta & Varias & $\begin{array}{l}\text { Mordisqueo en todas las } \\
\text { epífisis y las diáfisis y } \\
\text { apófisis } \\
\text { Marcas de corte sólo en } \\
\text { mandíbulas }\end{array}$ & $\begin{array}{l}\text { Macho grande } \\
\text { Ausente la cabeza, pero no } \\
\text { las hemimandíbulas } \\
\text { Columna vertebral y } \\
\text { costillar completo } \\
\text { Húmero izquierdo } \\
\text { Escápula } \\
\text { Coxal completo } \\
\text { Todas las piezas completas } \\
\text { y articuladas }\end{array}$ \\
\hline
\end{tabular}

Tabla 1: Inventario de material faunístico documentado durante la prospección en Kangerlussuak en 2017. Fuente: Elaboración propia.

Se trata de un matadero de caribúes. Los estudios de índices de aprovechamiento $^{13}$ generan una curva radicalmente distinta a la de los cazaderos tradicionales de las otras zonas estudiadas. En este caso se han desaprovechado las partes más carnosas. La ausencia de marcas de corte de descarnado, junto con la constatación explícita de la ausencia exclusiva del cráneo -sí quedaron en el cazadero las mandíbulas- en una carcasa de caribú adulto, visibilizan de nuevo la caza como práctica deportiva en la que la mayor parte de la presa queda en el lugar y la única acción de carnicería perceptible es la retirada del cráneo de los machos mayores como trofeo, quedando los de machos juveniles y los de hembras en el sitio de muerte. Se asume también el transporte de algunas extremidades, quedando finalmente las carcasas a merced de pequeños carroñeros, zorros y aves -cuervosque las descarnarían y dispersarían ${ }^{14}$.

\subsection{Sisimiut-Sarfannguaq: el caribú}

Sisimiut es una de las ciudades principales del oeste de Groenlandia y en origen fue una colonia danesa. Frente a ella existen múltiples yacimientos indígenas, desde

\footnotetext{
${ }^{13}$ BINFORD, L. R. Nunamiut Ethnoarchaeology. Nueva York: Academic Press, 1978; BINFORD, L. R. Bones: Ancient Men and Modern Myths. Nueva York: Academic Press, 1981.

${ }^{14}$ PASDA, K. Zur Taphonomie... Op cit.
} 
época Saqqaq a Inuit, como es el de Asummiut ${ }^{15}$. La población se encuentra en la propia costa y en ella vive un gran número de cazadores y pescadores dedicados en exclusiva a esas actividades. Sarfannguaq es un pequeño poblado en el que hay una factoría de pescado de la que depende fundamentalmente su población así como de la caza y de la pesca. Según el testimonio y el ejemplo vivo proporcionado por los informantes ${ }^{16}$, cazadores y pescadores mantienen, consciente e inconscientemente, muchos de los usos de caza, procesado y consumo del caribú aprendidos directamente de sus padres y abuelos. También aprendieron de sus antecesores todo lo relativo a la pesca del bacalao y a la caza de ballenas y focas.

Durante nuestra estancia en Sisimiut y Sarfanguaq, se pudieron analizar en el puerto decenas de carcasas de caribú y de foca que cotidianamente llegaban desde los cazaderos en las embarcaciones de los cazadores. En todos los casos llegaban las de caribúes desolladas, sin cabezas las de hembras o de machos juveniles y divididas por las lumbares. Así se transportan siempre:

- Los cuartos traseros (coxal articulado a las dos patas íntegras hasta las pezuñas) sin piel, cortada ésta a la altura de las falanges, generando marcas de corte transversales. En ocasiones las marcas quedaban en la distal de los metatarsos.

- La mitad delantera (patas delanteras con las partes bajas descartadas) unida al pecho y al cuello, eviscerada y sin piel. Las marcas de corte quedan en la última lumbar, en el extremo del cuello, en el interior del tórax y en la articulación de los radios-ulnas con los carpos y los metacarpos.

Pero el proceso de carnicería más completo lo pudimos analizar detalladamente en el caso de dos caribúes abatidos por Ludvin Enoksen, pescador de 23 años, el día 12 de agosto en los fiordos al sur de Sarfannguaq. Los cazadores detectaron desde la embarcación a los dos animales, una hembra adulta y un macho juvenil de alrededor de un año de edad -su cría- y Ludvin, armado solamente con una carabina del 22, escaló un escarpe y logró abatir las piezas con sólo dos tiros que afectaron en su trayectoria de entrada y salida al cuello y al pecho, en ambos casos sin generar marcas en los huesos. La hembra fue procesada por Ludvin Enoksen y la cría por Karl-Peter Berthelsen, empleando ambos un cuchillo metálico pequeño de unos $10-15 \mathrm{~cm}$ de filo, proceso primario para facilitar el transporte hasta la embarcación (Fig. 4):

\footnotetext{
${ }^{15}$ MØBJERG, T. y GRUMMESGAARD-NIELSEN, S. Saqqaq-Kulturen på Asummiut. Tidsskriftet Grønland. 1997, n. 5-7, pp. 239-259.

${ }^{16}$ Ólafur Rafnar Ólafsson, Hans Platou, Karl Vid Stein, Kund-Ferderik Glesia, Naaui Geremiassen, Ludvin Enoksen, Niki ¿?, Maligiaq ¿?, Henrik Ivéischer, Karl-Peter Berthelsen, John Enoksen, O. Vid Stein, Gustav Olsen, Julius Jeremicssen, Kim Hougaard, Nikolai Agustussen, Jeremias Sanimuinak, Barse Sr. Suendsen, Jens Johansen, Magdalene Berthelsen, Thomas Jorgensen, Jørn A. Thomsen, Søren Berthelsen y Kevin Vid Stein.
} 

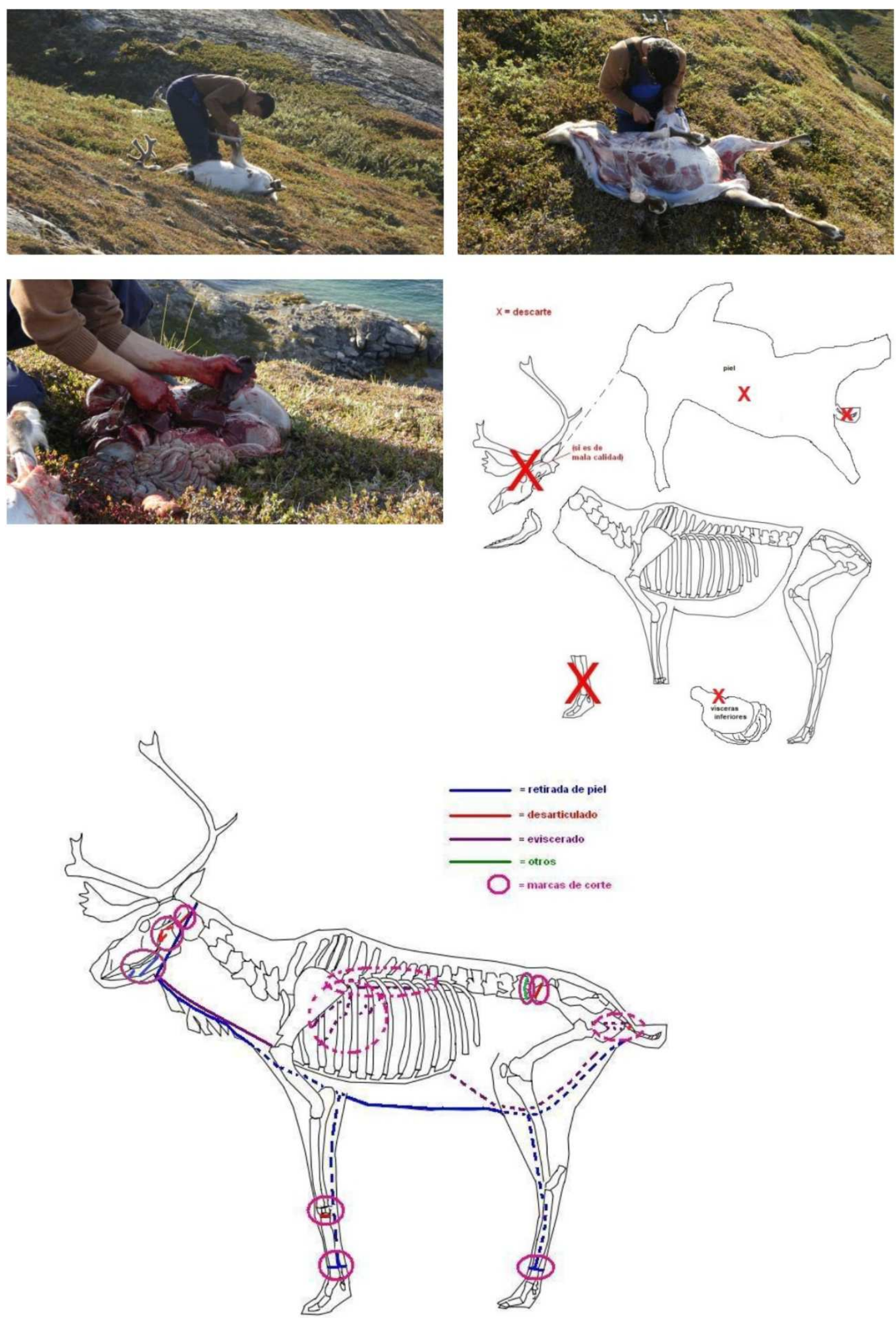

Fig. 4: Procesado del caribú en el sitio de muerte. Fuente: Fotografías y dibujos del autor. 
Hembra adulta:

- Corte perimetral para el despellejado en el metatarso izquierdo; genera marcas de corte.

- Idem en el metatarso derecho.

- Corte longitudinal en la cara interna o ventral de la piel de la patas traseras, desde el corte perimetral hasta el vientre; no genera marcas de corte.

- Corte longitudinal en la piel del vientre hasta el pecho, aprovechando para retirar las ubres; no deja marcas de corte.

- Corte perimetral en la pata delantera derecha a la altura del metacarpo; deja marcas de corte transversales al eje del hueso.

- Ídem en la pata izquierda.

- Corte en la piel de las patas, cara ventral, hasta el pecho; no deja marcas de corte en los huesos próximos.

- Ampliación del corte en la piel desde el vientre por encima del pecho hasta el cuello; no deja marcas de corte en el esternón por el cuidado del carnicero.

- Corte de la piel del cuello, desde el pecho hasta la parte baja de la mandíbula; no deja marcas de corte.

- Inicio del despellejado con el puño y el cuchillo por los costados y las patas; no quedan marcas de corte en ningún hueso.

- Eviscerado por la ingle izquierda; en principio sin marcas de corte.

- Cortes en la cara interna de las costillas y en la parte ventral de las vértebras para ayudar al completo eviscerado.

- Una vez extraídas las vísceras, se filetea parte del hígado para comerlo directamente crudo. También se realiza un corte en el estómago (lleno de comida y aún caliente) para introducir porciones del hígado que se calientan y mezclan con los vegetales en digestión. Tras pocos minutos esas porciones se consumen también.

- Antes de terminar de separar la piel el carnicero divide la carcasa por las lumbares y el sacro en dos partes; quedan marcas de corte.

- Finalización de la retirada de la piel de los cuartos traseros; las vértebras caudales quedan en la piel generándose en ellas marcas de corte.

- Vaciado con el cuchillo de los restos de intestino grueso en la parte del ano; marcas de corte en la parte ventral de sacro y en las caras internas de los coxales.

- Desarticulado de la pata delantera izquierda a la altura de los carpos; uso del cuchillo cortando los ligamentos y tendones perimetralmente para luego luxar y romper la articulación con ambas manos.

- Idem con la pata derecha.

- Finalización del despellejado de los cuartos delanteros.

- Desarticulado mediante corte y luxación del cráneo; se generan cortes en el foramen magno y en el axis-atlas.

- Despellejado de la mandíbula; quedan cortes en la cara exterior de las hemimandíbulas.

- Desarticulado de la mandíbula cortando las carrilladas con el cuchillo y forzando la unión con las manos, quedando cortes en los procesos de inserción en el cráneo. La mandíbula queda como contenedor portátil de la lengua, recurso que se pretende transportar. 
- Cortes de descarnado en la primera vértebra lumbar para enganchar la membrana y musculatura abdominal como cierre o tapa y generar una bolsa transportadora con el pecho. Se introduce el pecho de la cría en el pecho de la hembra adulta para su transporte.

Cría:

- Sección de la cabeza por el foramen; quedan marcas de corte en el cuello y en el cráneo.

- Corte perimetral para el despellejado en el metacarpo izquierdo; genera marcas de corte.

- Idem en la pata derecha.

- Idem en ambas patas traseras.

- Corte en el vientre y en el pecho para retirar la piel; no genera marcas de corte.

- Corte en la piel en la cara interna de las patas traseras para el despellejado; no quedan marcas en los huesos.

- Despellejado con el puño y el cuchillo de los costados y las patas.

- Desollado de la mandíbula desde la garganta a las carrilladas; quedan marcas de corte en la cara externa de ambas hemimandíbulas.

- Desarticulado de la mandíbula con el cuchillo, tirando con las manos para luxar la unión; genera marcas de corte.

- Finalización del desollado.

- Eviscerado empleando el cuchillo en el interior, generando marcas de corte en la cara interna de las costillas y en la parte ventral de las vértebras.

- Seccionado del animal en dos mitades por la última vértebra lumbar y por el sacro; quedan marcas de corte.

En el proceso se invirtieron unos 15 minutos, descontando los descansos para comer el hígado e iniciándose el transporte. Karl-Peter colocó uno encima de otro los dos cuartos traseros de los animales, sujetándolos por los metatarsos y colocándose la parte de los coxales tras los hombros. Ludvin cargó en el hombro ambos pechos, con el de la cría dentro del de la hembra. Nos dejaron transportar el rifle, los cuchillos y las dos mandíbulas con las lenguas en el interior (Fig. 5). En el matadero quedaron los metacarpos con las falanges de ambos animales, los cráneos sin mandíbula, las pieles y las vísceras. El resultado de este primer procesado es idéntico al constatado en 30 carcasas de caribúes estudiadas en el puerto de Sisimiut. 

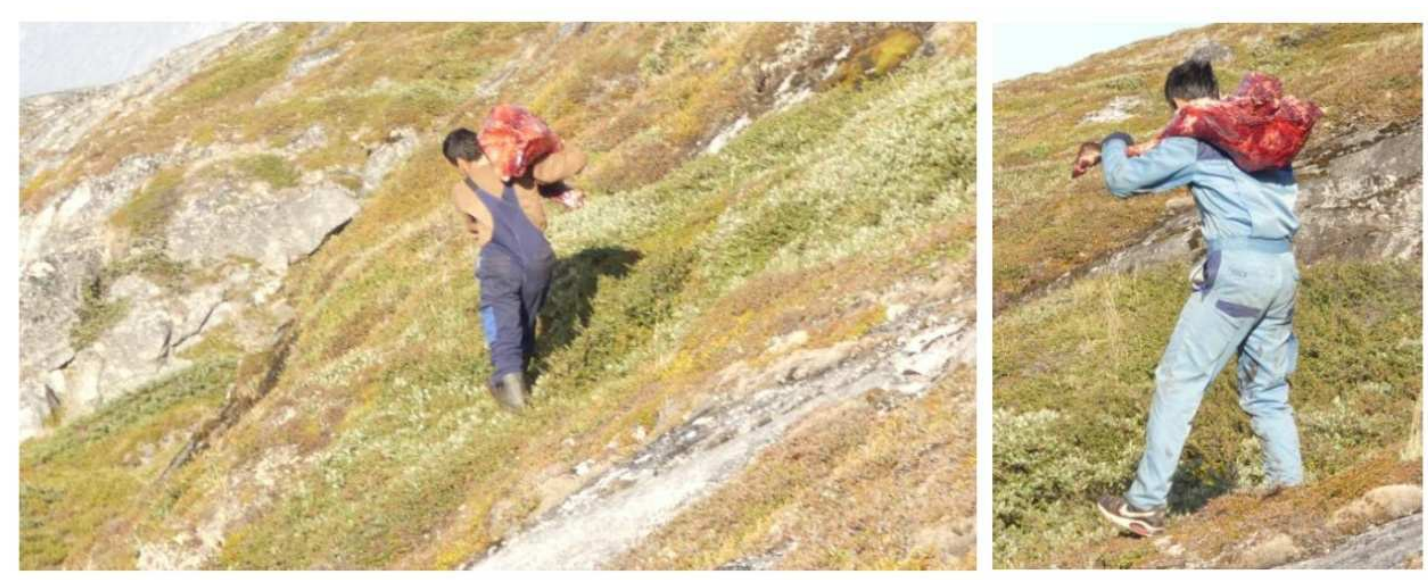

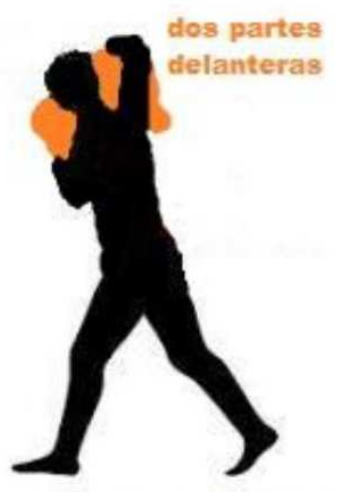

Porteador $\mathbf{1}=30+15 \mathrm{~kg}$ $45 \mathrm{~kg}$

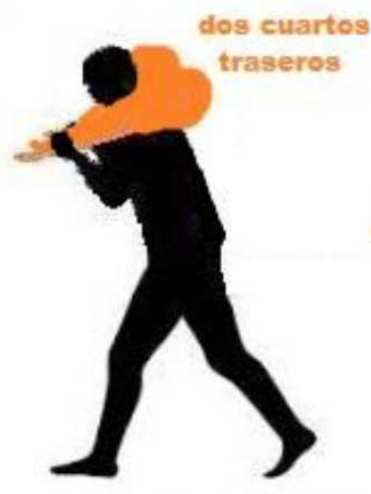

Porteador $2=20+10 \mathrm{~kg}$ $30 \mathrm{Kg}$

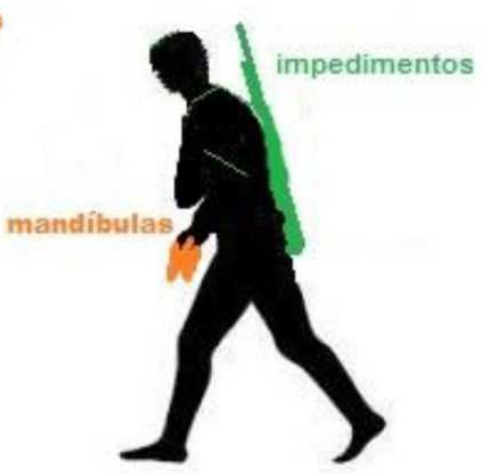

Porteadror $3=5+1 \mathrm{~kg}$

$6 \mathrm{~kg}$

SISIMIUTTSARFANNGUAQ/ITILLEQ

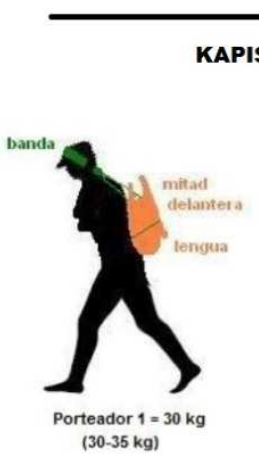

$(30-35 \mathrm{~kg})$

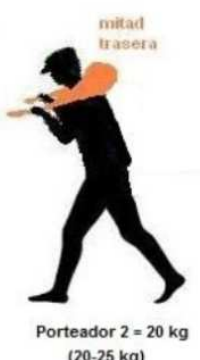

$(20-25 \mathrm{~kg})$

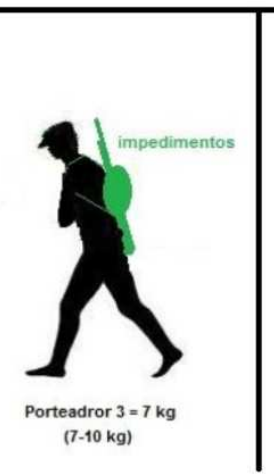

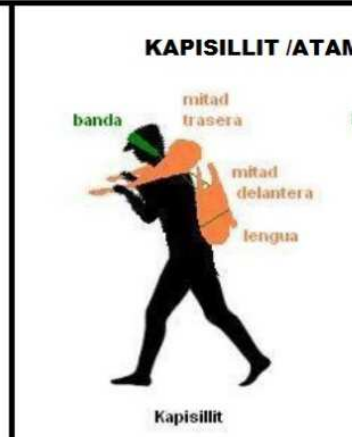

Kapisillit

Fig. 5: Transporte del caribú en el área de Sisimiut-Sarfanguaq-Itilleq y comparación con los usos propios de Atammik y Kapisillit. Fuente: Lámina del autor.

En la embarcación se realizó otro proceso de descuartizado para el reparto de la presa y su almacenamiento (Fig. 6). Realizaron la labor Ludvin Enoksen, Karl-Peter Berthelsen y Karl Vid Stein. Además de cuchillos, se empleó un machete y se alternó el procesado de ambos animales. La secuencia duró aproximadamente una hora:

- Separación de las paletillas de la hembra adulta; no genera marcas de corte.

- Separación de la membrana del vientre; se guarda; no genera marcas de corte en los huesos asociados. 
- Sección del pecho por la parte distal de las costillas, separando el esternón; genera marcas de corte de seccionado.

- Separación de pulmones y corazón, dejando algunas marcas de corte en la cara interna de las costillas.

- Sección a cuchillo y machete del costillar izquierdo, cortando la cabeza de las costillas y las apófisis de las vértebras. Forzando con las manos, se quiebra y se termina de separar, generando fracturas.

- Ídem con el otro costado.

- División por la mitad del paquete del espinazo, a la altura de las dorsales, generándose marcas de corte.

- Mismos pasos sobre la parte delantera del animal pequeño.

- Retirada de la cola de la cría que se había mantenido, a diferencia de la del animal mayor que se abandonó en el matadero con la piel.

- Desarticulado de las partes bajas de las patas traseras, mediante corte perimetral de los tendones a la altura del tarso y luxación manual de la articulación; quedan marcas de corte en ambos animales. Las patas se descartan.

- Desarticulado de los fémures y tibias de ambos animales del coxal; se generan marcas de corte en fémures y coxales.

- Limpieza de la suciedad y restos de membranas de cada paquete. Durante el proceso se comen pequeñas porciones de carne cruda. 


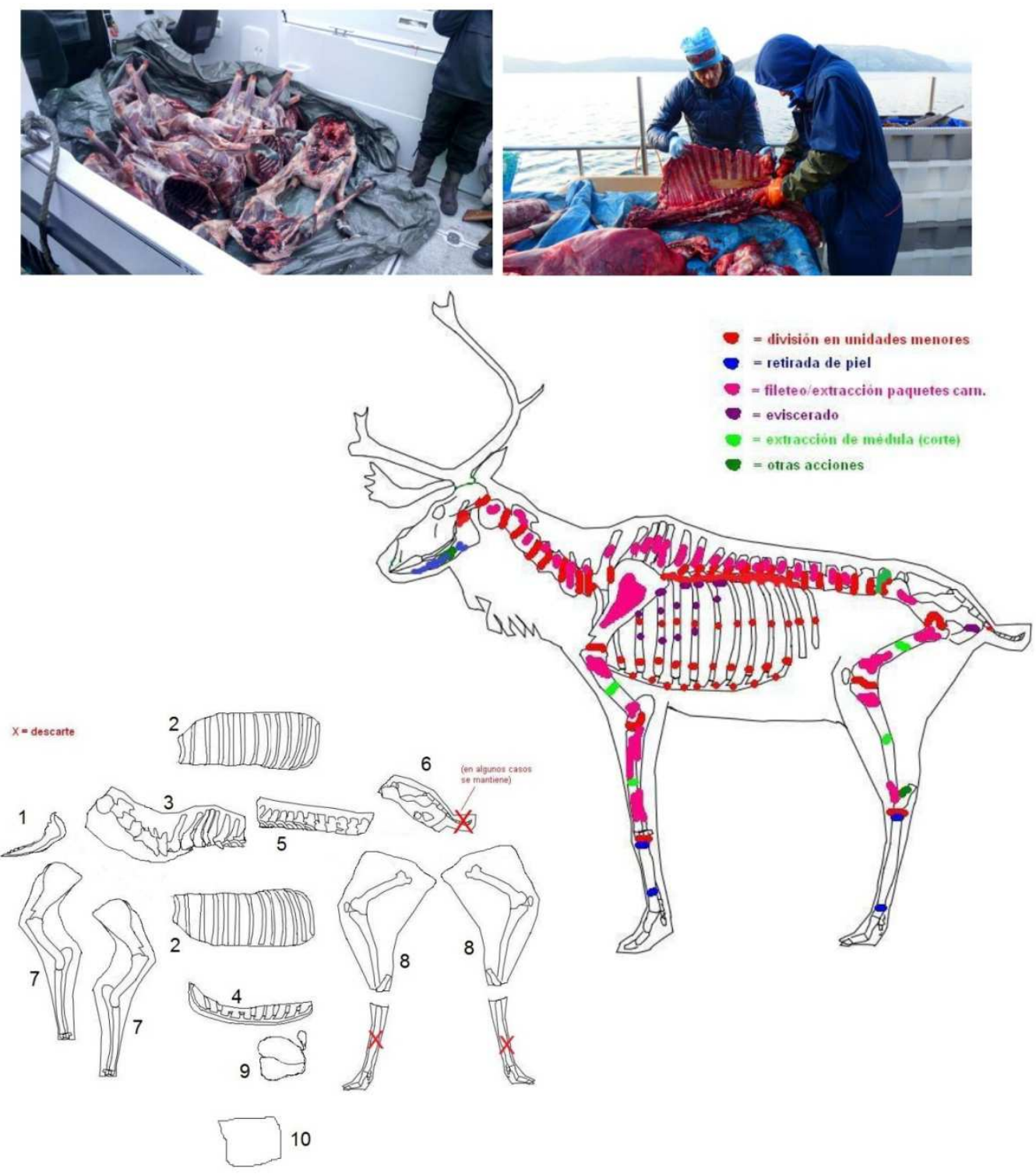

Fig. 6: Carcasas de caribú en Sisimiut transportadas desde el punto de muerte y procesado del caribú para su división en unidades de almacenamiento y reparto. Abajo: porciones de almacenamiento y reparto y marcas de corte tras todas las acciones de carnicería y consumo. Fuente: Fotografías y dibujos del autor.

Ludvin indicó explícitamente que todo el proceso lo había aprendido de su padre, quien le parecía personalmente mucho más rápido y preciso en el uso del cuchillo y en los cortes de lo que aún era él.

Los paquetes resultantes de esta segunda secuencia de carnicería son los siguientes; el número de inventario se indica en la Fig. 6.

0 = Cráneo; si se transporta desde el punto de muerte por ser de macho grande .

1 = Mandíbula.

$2=$ Costillares $(\mathrm{x} 2)$.

$3=$ Mitad del espinazo con las cervicales y parte de las dorsales. 
4 = Esternón con la parte distal de las costillas.

5 = Mitad del espinazo con parte de las dorsales y las lumbares.

6 = Cadera.

7 = Pata delantera, consistiendo el paquete en escápula, húmero y radio/ulna con carpal (x2).

8 = Pata trasera, consistiendo el paquete en húmero y tibia, con tarsal (x2).

9 = Corazón.

10 = Membrana y musculatura del vientre.

Además de la observación directa de los procesos de caza y carnicería primaria y secundaria, se realizaron prospecciones para entender y comprobar la visibilidad de esas acciones en el registro faunístico. Aprovechando partidas cinegéticas se prospectó en Sarfannguaq una de las zonas de caza veraniega de caribú. Se trata de un área al norte de la población, al otro lado del fiordo, donde se analizaron e inventariaron todos los restos óseos detectados (Tabla 2).

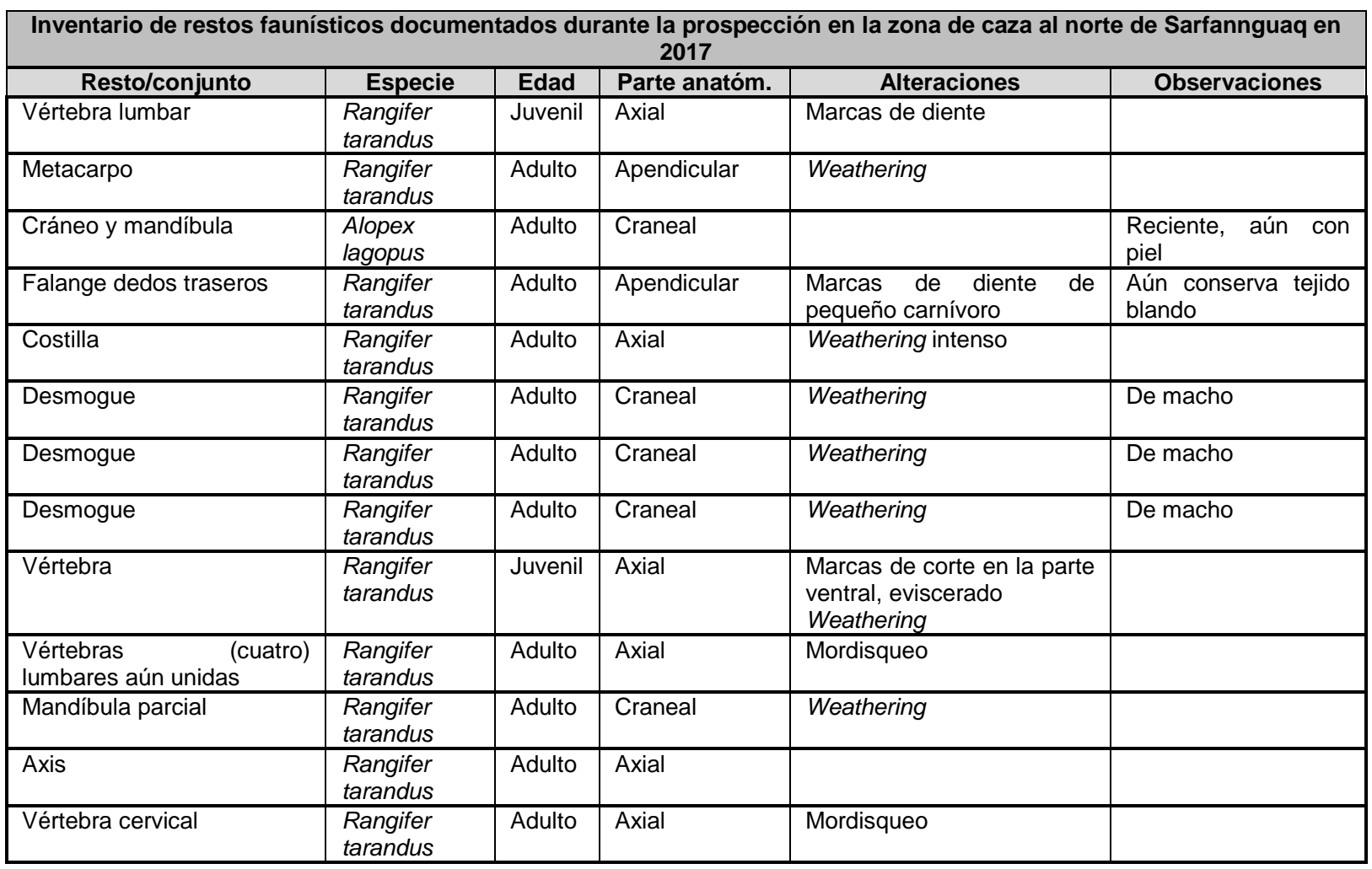

Tabla 2: Inventario de restos faunísticos documentados durante la prospección en la zona de caza al norte de Sarfannguaq en 2017. Fuente: Elaboración propia.

Se documentó además el sistema de inuksuit ${ }^{17}$, todos visibles desde la ruta que tomamos en la cacería. Según los informantes parece que la mayoría de las construcciones pétreas conforman un sistema de "espantapájaros" destinado a influir en las rutas de los caribúes, conduciéndolos por determinados caminos adecuados para la caza. Son también destacables unas tumbas Thule en la parte sur del área

\footnotetext{
${ }^{17}$ HALLENDY, N. Inuksuit: Semalithic Figures Constructed in the Canadian Arctic. $25^{\text {th }}$ Annual Meeting of the Canadian Archaeological Association. Ontario, 1992; HALLENDY, N. The Silent Mesengers. Equinox. 1997, n. 85, pp. 36-46; DOMÍNGUEZ-SOLERA, S. D. Inuksuit en el oeste... Op. cit.
} 
prospectada. Pero la estructura pétrea detectada más destacable para los fines de este estudio fue un escondrijo de carne de caribú (ver Fig. 3) localizado a media ladera de un monte aprovechando un farallón rocoso. En el interior del escondrijo había al menos piezas de dos caribúes adultos cubiertas de piedras del entorno. Debieron realizarse en momentos en los que había nieve alrededor para conservar la carne. El contenido no se recuperó, se pudriría en primavera y verano y, finalmente, quedarían los huesos descarnados. No se pudo excavar el escondrijo por las circunstancias en las que se produjo el hallazgo.
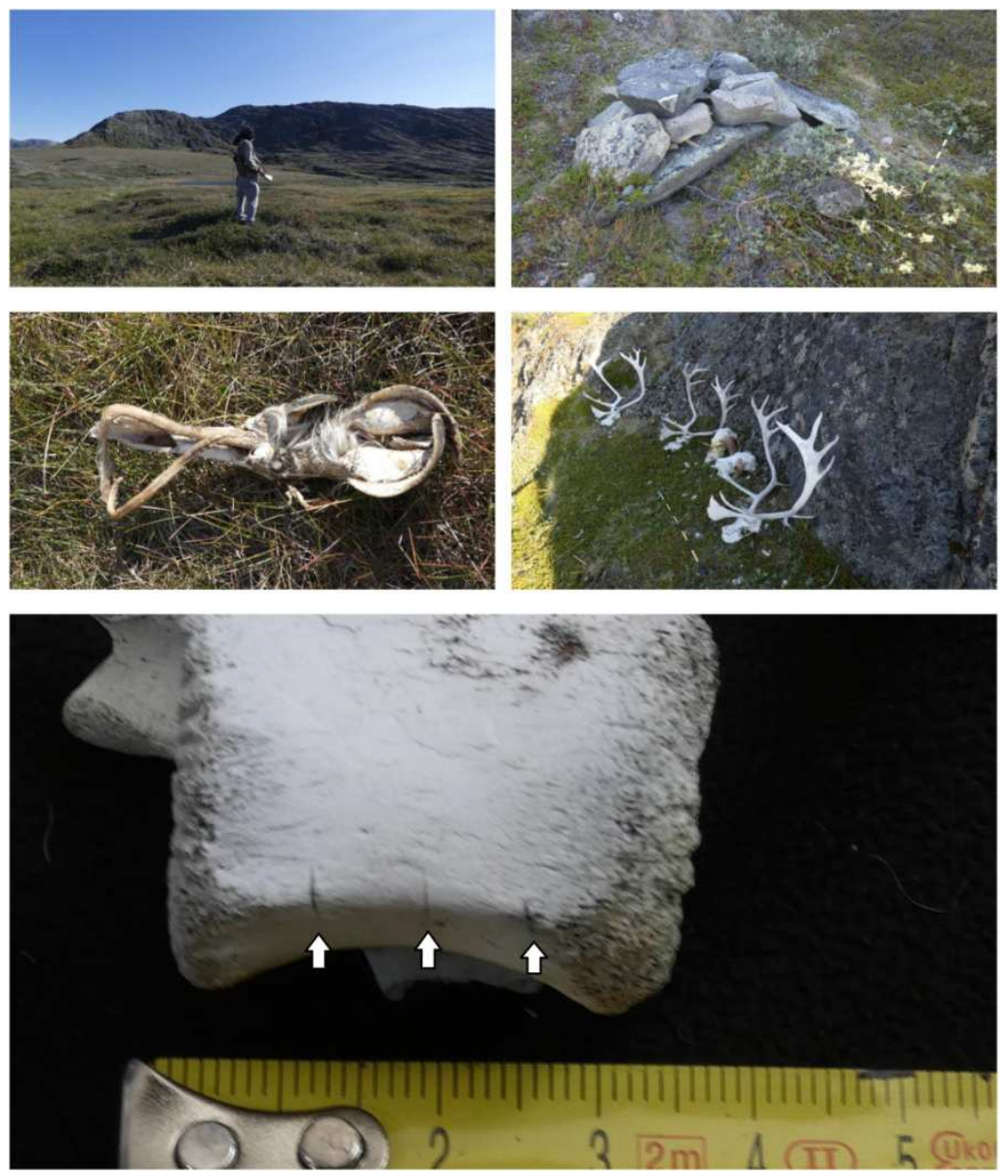

Fig. 3: Sarfannguaq. De arriba hacia abajo y de izquierda a derecha: zona de caza prospectada; escondrijo antiguo de carne; restos esqueléticos entre las casas del pueblo de Sarfannguaq (parte distal de pata trasera de caribú), cabezas de grandes machos de caribú y marcas de corte en la parte inferior de una vértebra producida por eviscerado. Fuente: Fotografías del autor.

También se prospectó el propio pueblo de Sarfannguaq, alrededor de las casas y en las calles. La intención era cotejar y contrastar el registro de un cazadero en relación con el sitio al que se transportan y donde se consumen las porciones de caribú. No se hizo un inventario estadístico de los restos, ya que en el pueblo se arrojan los restos a contenedores, se retira la basura y también resultó imposible estudiar lo guardado en congeladores en el interior de las casas. Pero la descripción genérica de los tipos de elementos que se exponen y descartan en el poblado, tras los últimos pasos del procesado y el consumo humano y por parte de los perros, es enormemente elocuente para comprender ciertos detalles de la cadena operativa completa. 
En primer lugar, se detectaron los paquetes cárnicos de caribú que se generan durante el descuartizamiento primario para el reparto y el almacenado secándose en los porches de las casas, según se acostumbra en esta parte y en otras poblaciones del oeste de Groenlandia.

En segundo lugar, destaca la presencia de cabezas de grandes machos de caribú y de buey almizclero, bien pudriéndose o bien expuestas, junto a las casas o en paredes de roca. En el apartado de discusión y conclusiones se precisarán las implicaciones culturales de tal práctica.

Se encontraron huesos apendiculares largos superiores seccionados transversalmente por la mitad exacta mediante un golpe enérgico. Según se pudo comprobar en la campaña de 2012, es una técnica de extracción del tuétano propia de esta zona del Ártico, en la que se emplea después un vástago para extraerlo de las dos porciones ${ }^{18}$. También se documentaron vértebras lumbares y cervicales con cortes en la parte ventral, ubicación obligada de las huellas de cuchillo cuando se eviscera una carcasa tras el acceso primario a la misma.

Se documentaron múltiples conjuntos de patas traseras de caribú, articuladas desde las tibias hasta las falanges. Algunas de ellas tenían aún piel y tejidos conectivos, con huellas de percusión para la extracción de tuétano de las tibias y marcas de corte para el descarnado de los paquetes cárnicos de las tibias, aún sin desarticular la pata.

Por último, se constataron los gestos de descuartizado del costillar empleando sólo un cuchillo, con la huella característica del corte guía en uno de los lados de la costilla y la factura en el antagónico, rotura provocada por la acción del tronchado con las manos de los dos trozos de costillar por la sección guía ${ }^{19}$.

Los restos de caribú no craneales mencionados eran tanto juveniles como adultos, lo que indica que para el consumo se cazan tanto machos grandes como hembras adultas y crías.

Además de la forma tradicional de carnicería que emplea sólo un cuchillo pequeño para realizar todas las acciones del proceso, se encontraron también ejemplos puntuales del uso de una sierra para seccionar longitudinalmente la columna vertebral. Hay también marcas esporádicas de dientes de perros, ya que generalmente no campan sueltos por el pueblo y se les alimenta en sus corrales o casetas.

Es necesario precisar que, aunque era el taxón mayoritario, no todos los restos del pueblo de Sarfannguaq eran de caribúes. También se documentaron restos de ave, la hemimandíbula de una ballena expuesta en el porche de una casa, y huesos largos superiores de foca con marcas de corte para el descarnado. Por último, destáquese la presencia en un porche de un ala de gaviota, abundante y fácil de abatir, pero que no se consume pues su carne se considera culturalmente mala; los

\footnotetext{
${ }^{18}$ DOMÍNGUEZ-SOLERA, S. D. Estudio etnoarqueológico. Op. cit.

${ }^{19}$ Ibídem.
} 
informantes nos explicaron que tanto hoy como en el pasado se empleaba esa parte como escoba para limpiar el suelo.

\subsection{Sisimiut-Sarfannguaq: focas}

Habiendo observado previamente las diferentes etapas de la carnicería, el transporte y el consumo de la foca barbuda, la groenlandesa o la ocelada (focas verdaderas, familia Phocidae), el día 16 de agosto de 2017 se pudo observar con detalle la secuencia completa de caza y primer procesado de tales animales. Se buscaron focas -puisi en groenlandés- al sur de Sisimiut con el cazador Nikolai Agustusen, de 35 años, que se dedica fundamentalmente y a tiempo completo a su caza, aunque también pesca y caza otras especies terrestres y marinas, de lo que viven él y su familia.

La técnica actual de caza de focas en verano, en Sisimiut y en otras zonas del oeste de Groenlandia, consiste en navegar hasta el área en la que se encuentran los animales, oteando la superficie del mar en calma a la espera de la aparición de la cabeza para respirar. En ese momento se les dispara, preferentemente con una carabina del 22, izando rápidamente la presa con un gancho antes de que muera y se sumerja. En verano, con menos grasa corporal, las focas se hunden antes: el cazador abatió dos animales y sólo pudo recuperar uno, una hembra grande. Tras el primer disparo en el cuello y antes de izarla la remató con un disparo en la cabeza.

Nos desplazamos al campamento de caza de Nikolai, donde descuartizó el animal en el sitio donde suele hacerlo: una bahía natural, en la que se desembarcó en marea baja. Empleando sólo un cuchillo muy afilado ejecutó las siguientes acciones (Fig. 7):

- Seccionado de la aleta delantera derecha por el carpal, seccionando al mismo tiempo piel, carne y hueso; quedan marcas de corte evidentes.

- Idem con la aleta delantera izquierda; se apartan.

- Corte perimetral de la piel de las aletas traseras a la altura de los metatarsos, sin seccionar las patas aún; quedan marcas de corte.

- Corte en la piel y grasa de la parte ventral desde la barbilla al ano. Inicio del desollado a cuchillo. A causa de una pequeña rotura realizada por el cuchillo el cazador no guardaría la piel ya que no podría venderla.

- Descuerado de ambos costados; no quedan marcas de corte.

- Corte del pecho longitudinalmente, quedando marcas de corte en el esternón y las costillas asociadas. Las vísceras quedan expuestas.

- Corte del pubis por la sínfisis, para abrir la cadera y facilitar el eviscerado; quedan marcas de corte.

- Eviscerado mediante el cuchillo, quedando marcas de corte en la cara interna de las costillas, en la parte ventral de las vértebras y en el interior de la cadera.

- Corte por la junta entre vértebras y costillas; la parte del lado derecho, seccionando el hueso (cabezas y apófisis) en algunos casos, aunque se produce por lo general la desarticulación de los elementos; cortes y fracturas asociadas.

- Idem con el lado izquierdo.

- Corte de la parte del esternón, que se arroja al mar. 
- Limpieza en el mar de la sangre de los paquetes cárnicos/grasos que se van generando, amontonándolos sobre una piedra.

- Separación del espinazo completo por las lumbares a la altura del sacro; se generan las lógicas marcas de corte.

- Seccionado de las aletas traseras que se arrojan al agua lo mismo que las delanteras.

- Descuerado de la cara para separar la cabeza; produce marcas de dientes en el cráneo y las hemimandíbulas; se separa así finalmente del resto de la carcasa y se descarta por las razones mencionadas.

- Se deslían los intestinos y se limpian en el agua, anudándose para guardarse.

- La cadera con los fémures y las tibias de ambas patas quedan en un mismo paquete, sumando un total de $30 \mathrm{~kg}$ de carne, grasa y huesos. Todo el proceso duró apenas 30 minutos. Éste es el inventario:

- Aletas delanteras (x2); se descartan.

- Aletas traseras (x2); se descartan.

- Cabeza; se descarta.

- Piel, en este caso se descarta.

- Hígado; se guarda.

- Manojos del intestino delgado (x2); se guardan.

- Vísceras (resto); se descartan.

- Costillares (x2); se guardan.

- Caderas con fémures y tibias en unión; se guarda.

- Esternón; se descarta.

- Espinazo completo; se guarda. 

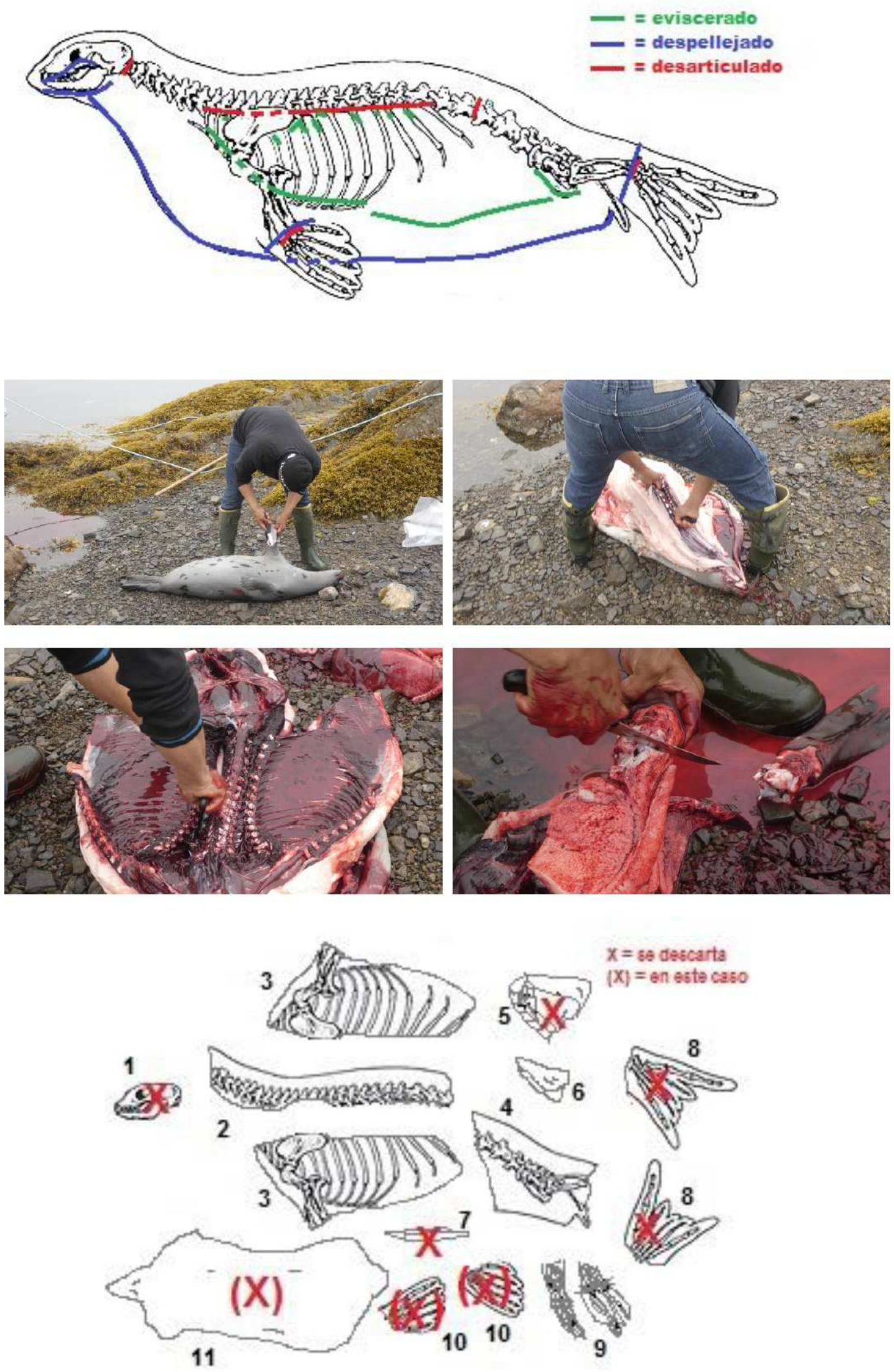

Fig. 7: Procesado de una foca hembra por Nikolai Agustusen. Fuente: Fotografías y dibujos del autor. 
Aprovechando la bajamar, se prospectó el área del campamento para identificar el registro óseo; el inventario de materiales generado, todos de foca, es el siguiente correspondiendo los números de la lista a los consignados en el plano adjunto (Fig. 8):

1) 2 hemimandíbulas aún con tejidos blandos del mismo animal; marcas de corte.

2) 2 aletas traseras del mismo animal con piel; marcas de corte.

3) 1 costilla seccionada, parte distal.

4) 1 cráneo parcial: la mitad delantera hasta la altura de las órbitas.

5) Media mandíbula con dientes.

6) 1 costilla, parte proximal seccionada.

7) 1 fragmento de cráneo: el hueso frontal con restos de tejidos blandos.

8) Espinazo completo con restos de carne.

9) Piel de foca.

10) Vísceras de foca.

11) Cráneo de foca completo articulado con espinazo, aún con restos de tejido blando.

12) Fragmento de cadera, seccionado.

13) Fémur completo; señales producto de la intemperie.

14) Fragmento de hemimandíbula derecha, con señales de la intemperie y marcas de corte.

15) Fragmento de hemimandíbula.

16) + 2 fragmentos no identificados. 

oeste de Groenlandia.
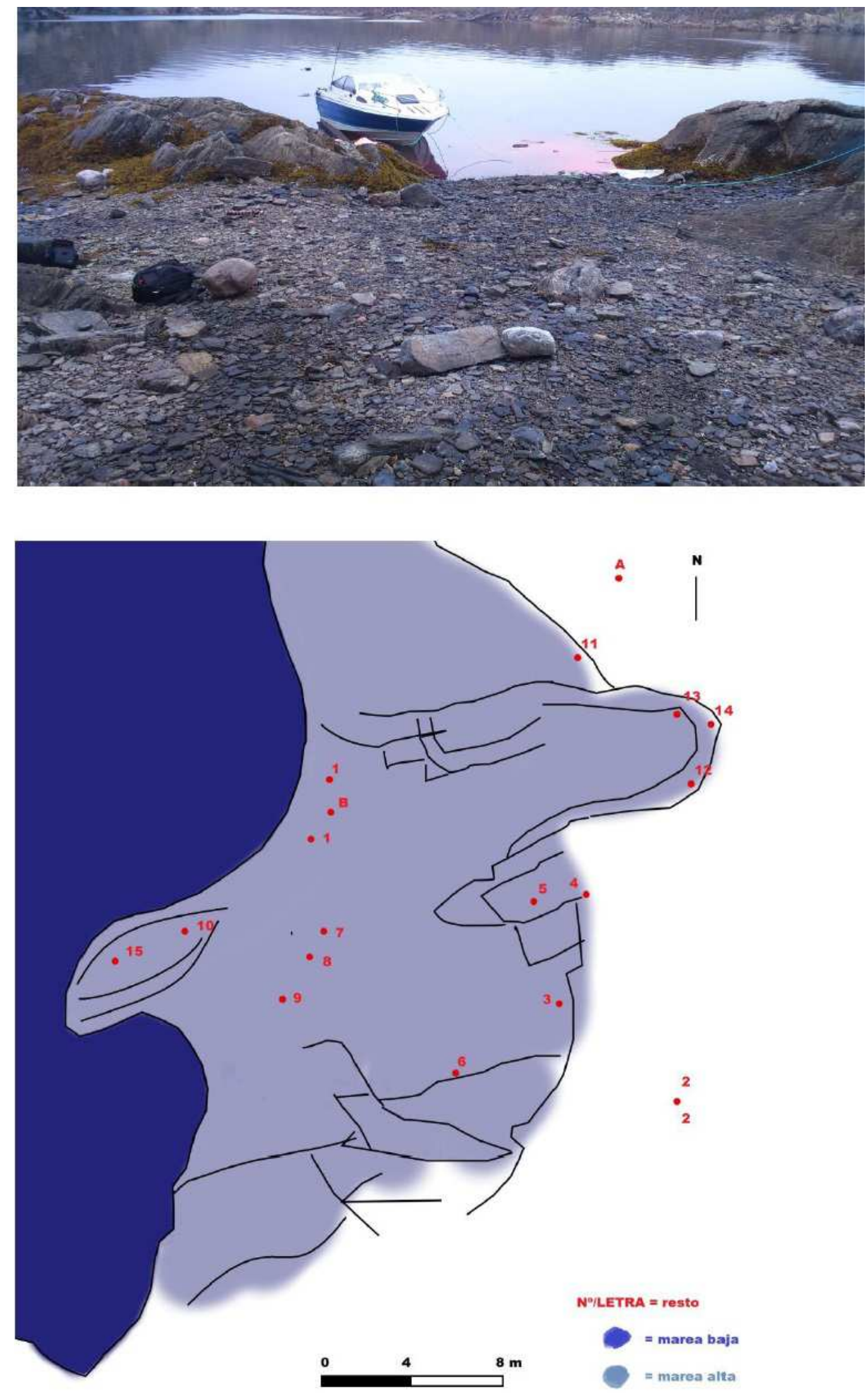

Fig. 8: Distribución de restos esqueléticos en la costa del campamento de Nikolai Agustusen. Fuente: Fotografía y plano del autor. 
También se documentó una mandíbula de ballena grande (alguna del género Balaenoptera), no cazada por Nikolai pero transportada allí desde el punto en el que fue encontrada y una hemimandíbula de marsopa Niisa (Phocoena phocoena).

Los restos de foca que se descartan y los restos de lo que se consume en el campamento se tiran siempre al mar. En el apartado de discusión se destacarán las causas e implicaciones simbólicas y culturales de tal hecho, a priori anecdótico. Todos los restos de foca encontrada, menos dos aletas, se encuentran en la acumulación producida por la marea al empujar los restos arrojados por el mar a la costa. Es una forma de acumulación en sitios costeros de poca corriente, como ocurre en esta bahía no expuesta a la acción de las olas. Los elementos sólo presentan marcas antrópicas, pero el descarnado completo lo provocan otros agentes no humanos tales como los peces, que no generan marcas de dientes.

Otras carcasas de foca observadas en el puerto de Sisimiut y otros puntos de la zona visitada, demuestran que los paquetes generados, tanto los consumidos como los descartados, son los que siempre se producen dentro del modelo ideal reproducido por todos los cazadores de la zona. En mercados de productos tradicionales de consumo para groenlandeses, se observó cómo se podían subdividir aún más los paquetes antes de cocinarlos. También se obtuvo información sobre qué partes eran las más consumidas por las personas y cuáles se solían dar a los perros: en la mayoría de los casos el paquete de la cadera con los fémures y las tibias (Fig. 11). 

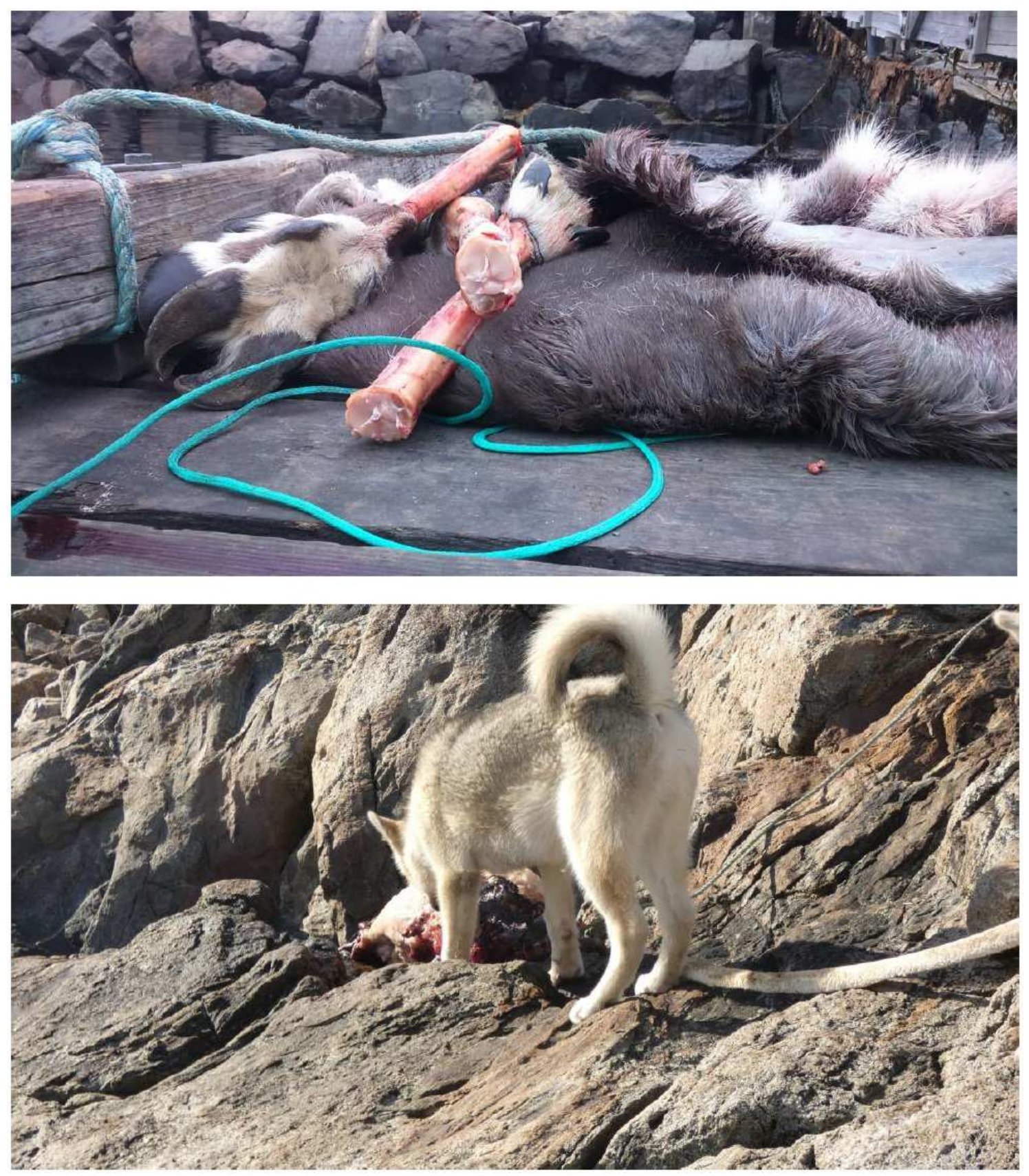

Fig. 11: Parte distal de las patas y piel de caribú descartadas en el embarcadero del puerto de Sisimiut y cuartos traseros de foca para alimentar a los perros de Julius Jeremicssen. Fuente: Fotografías del autor.

\subsection{Pesca del bacalao y otros datos}

También se realizaron en Sisimiut y Sarfannguaq encuestas y observaciones sobre la pesca, procesado y consumo del bacalao (Gadus morhua), saarullik en Groenlandés. Los datos no difieren demasiado de los observados más al sur, en el área de Nuuk y Atammik ${ }^{20}$, capturándose este animal mediante redes o por pesca manual con aparejo. Según los informantes ${ }^{21}$, la segunda es la más antigua y

\footnotetext{
${ }^{20}$ DOMínGUEZ-SOLERA, S. D. Los Inuit. Caza y pesca... Op. cit.; Etnoarqueología y el mar... Op. cit.

${ }^{21}$ Pescadores Karl Vid Stein (42 años) y Julius Jeremicssen (60-65 años).
} 
tradicional, heredada de las técnicas de padres y abuelos y constatadas también arqueológicamente por el empleo de señuelos con materiales tradicionales preindustriales ${ }^{22}$. Consiste en un largo sedal con un señuelo artificial aplomado en la punta y en cabos de un metro con más señuelos ligeros en sus extremos. El sedal se despliega desde la barca, realizándose tirones enérgicos con el brazo e izando los bacalaos a mano cuando pican. Del roce de la línea de nailon en la borda, quedaban múltiples muescas en la barca del pescador veterano Julius Jeremicssen (Fig. 9). ¿Existen pruebas de la misma técnica con huellas similares en restos de bordas de umiaq arqueológicos?

${ }^{22}$ HANSEN, K. Jigs from Greenland. En: GILBERG, R. y GULLøW, H. C. (eds.). Fifty Years of Arctic Research. Anthropological Studies from Greenland to Siberia. Copenhague: National Museum of Denmark, 1997, pp. 149-156. 

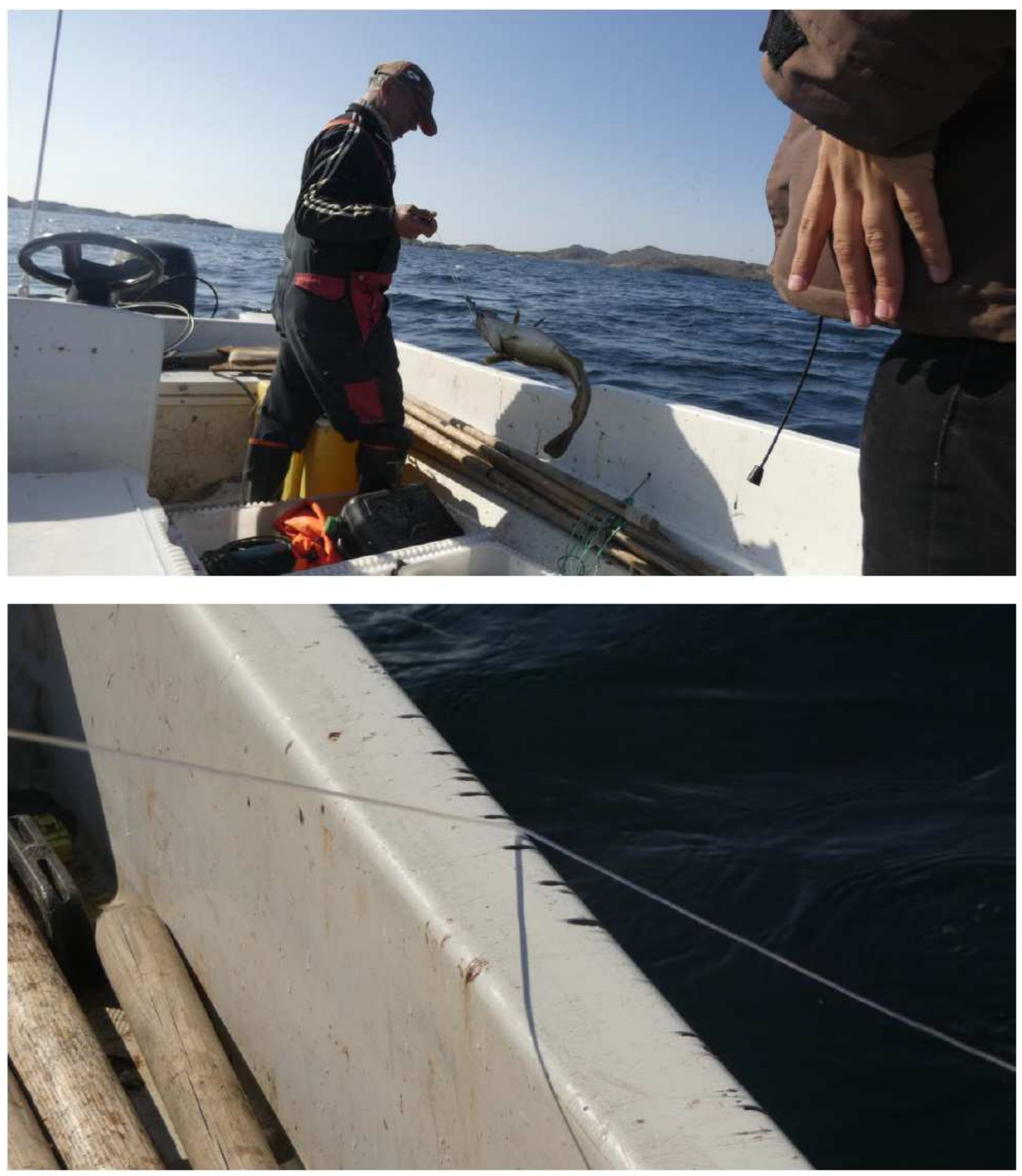

Fig. 9: Pesca con aparejo del bacalao por Julius Jeremicssen. Fuente: Fotografías del autor.

Aunque en el pasado se pudiesen emplear trampas, la pesca mediante redes es una herencia danesa -bundgarn es red en danés-. El bacalao se adentra en la red soportada por boyas, se cierra al recogerse y se iza a las embarcaciones, donde se eviscera, se retira la cabeza y, si procede, se introduce en hielo para su transporte. Los informantes de Sisimiut nos explicaron que durante el proceso se come cruda la carne que recubre la zona inferior de la mandíbula, pues se considera un manjar.

En el campamento de caza de Nikolai Agustusen, observamos el final del procesado antes del consumo, algo diferente al observado en otras partes del oeste de Groenlandia: se quitan las cabezas y la espina, pero se divididen los dos lomos en tiras para su secado sobre rejillas, en lugar de mantenerlos unidos generando un 
gran filete, como se documentó en Kapisillit ${ }^{23}$ o colgándolos con la cabeza a secar en un soporte de madera y/o cuerdas, como se documentó en Atammik ${ }^{24}$.

Durante el trabajo de campo se conoció a varias mujeres cazadoras. A las 7 mujeres entrevistadas en el año 2012 habría que sumarles otras 5 encuestadas en 2017. Del total de 12 mujeres inuit, 6 participaban activamente en actividades de caza y pesca y todas ellas habían tenido contacto con ellas al menos en su infancia y en su contexto familiar, conocían sus rudimentos y las consideraban explícitamente como el centro de su esencia cultural ancestral ${ }^{25}$.

También se entrevistó a los informantes sobre cómo se educaron en la caza y la pesca, comprobándose la aseveración en la bibliografía producida por los propios inuit ${ }^{26}$ de la transmisión de hábitos, técnicas y gustos alimenticios de padres e hijos durante generaciones, lo que perpetúa las tradiciones animistas aún tras la occidentalización y la pérdida del significado original. Por último, se constató cómo la caza y la pesca siguen siendo reivindicadas como parte de la identidad groenlandesa actual, de forma consciente e incluso apologética, siendo símbolo omnipresente y sinónimo de "libertad" para quienes eligen estas actividades frente a los oficios occidentales. Desarrollar este tema excedería los fines del presente artículo, aunque sí se presenta en el documental ya editado que se realizó en paralelo a la investigación científica ${ }^{27}$.

\section{Recapitulación, discusión y conclusiones}

Recapitulando la esencia de los resultados arriba expuestos: En Kangerlussuaq se obtuvieron interesantes testimonios sobre la caza tradicional y sobre mujeres cazadoras, pero sobre todo se pudo analizar "etno-zooarqueológicamente" un contexto de caza de caribú y uno occidentalizado de buey almizclero, demostrando que la intromisión de los usos globalizados también es visible tafonómicamente, tema avalado por testimonios diversos. El estudio de los elementos presentes en los

${ }^{23}$ DOMíngueZ-SOLERA, S. D. Los Inuit. Caza y pesca... Op. cit.; Domínguez-Solera, S. D. "DOMÍNGUEZ-SOLERA, S. D. Etnoarqueología y el mar... Op. cit..

${ }^{24}$ Ibídem.

${ }^{25}$ En la tradición inuit algunas mujeres lo fueron, siendo famosas y prestigiosas. Véase HANSEN, K. Nuussuarmiut- Hunting Families on the Big Headland. Copenhague: The Commission for Scientific Research in Greenland, 2008. No es extraño que las mujeres cacen animales, pese a la aseveración tradicional de que en las comunidades de cazadores-recolectores la caza es ámbito exclusivo masculino y la recolección femenino. Se observan solapamientos que añaden complejidad y recorrido al debate. Aunque, efectivamente, las mujeres se dediquen con más intensidad a acciones de recolección en la mayoría de las etnias forrajeadoras conocidas, al igual que ocurre en el contexto inuit y por ejemplo: las Agta son activas cazadoras. ESTIOKO-GRIFFIN, A. y GRIFFIN, P. B. Woman the Hunter: The Agta. En: DAHLBERG, F. (ed.). Woman the Gatherer. New Haven: Yale University Press, 1981, pp. 121-151. La participación en actividades cinegéticas por parte de mujeres es variable según las etnias, pero no un ámbito totalmente excluyente, al igual que los hombres ejecutan también labores de recolección. Ver DOMÍNGUEZ-SOLERA, S. D. Man the Gatherer: Los Ju/'hoansi de la Nyae Nyae (Namibia) y la actividad recolectora masculina durante las expediciones de caza. En: DOMíNGUEZ-SOLERA, S. D. (coord.). Etnoarqueología Total: Para todas las épocas, para todas las sociedades, para todos los temas. Vol. 1. Cuenca: UIMP; Diputación de Cuenca, 2018, pp. 19-29.

${ }^{26}$ VV.AA. The Inuit Way. A Guide to Inuit Culture. Nunavut: Pauktuutit Inuit Women of Canada, 2006.

${ }^{27}$ El Último Confín: Los Inuit del Oeste de Groenlandia. ARES Arqueología y DOJO Producciones. 2018. 
cazaderos y sus índices de aprovechamiento (según datos sobre el MAU, MGUI, etc. de Binford ${ }^{28}$ ) demuestra, con una gráfica de curva casi plana aunque tendente al tipo "gourmet", el abandono total o casi total de carne, grasa y vísceras de los animales cazados a los que solamente se les quitó la cabeza (Tabla 3, Fig. 10). En cambio, el estudio del cazadero de Sarfannguaq (Fig. 10, Tabla 4) demuestra un transporte de la carcasa coherente con el uso tradicional para consumo. La interpretación de ambos contextos se coteja y corrobora con los episodios de caza, carnicería, consumo y descarte presenciados personalmente en el periodo de convivencia con los informantes.

\begin{tabular}{|l|c|c|c|c|c|}
\hline \multicolumn{6}{|c|}{ Zona de caza de Kangerlussuaq (kill site). Sólo caribú. } \\
\hline & Total & Frecuencia & MAU & \%MAU & MGUI \\
\hline Desmogues & 0 & 2 & 0 & - & 1,02 \\
\hline Cráneo & 1 & 1 & 1 & 40 & 8,74 \\
\hline Mandíbula & 1 & 1 & 1 & 40 & 30,26 \\
\hline Atlas & 1 & 1 & 1 & 40 & 9,79 \\
\hline Axis & 1 & 1 & 1 & 40 & 9,79 \\
\hline Cervicales & 5 & 5 & 1 & 40 & 35,71 \\
\hline Torácicas & 13 & 13 & 1 & 40 & 45,53 \\
\hline Lumbares & 11 & 7 & 1,5 & 60 & 32,05 \\
\hline Costillas & 26 & 26 & 1 & 40 & 49,77 \\
\hline Esternón & 1 & 1 & 1 & 40 & 64,13 \\
\hline Escápula & 2 & 2 & 1 & 40 & 43,47 \\
\hline Húmero & 2 & 2 & 1 & 40 & 43,47 \\
\hline Radio/ulna & 2 & 2 & 1 & 40 & 26,64 \\
\hline Carpales & 3 & 2 & 1,5 & 60 & 15,53 \\
\hline Metacarpo & 3 & 2 & 1,2 & 48 & 12,18 \\
\hline Pelvis & 1 & 1 & 1 & 40 & 47,89 \\
\hline Fémur & 5 & 2 & 2,5 & 100 & 100 \\
\hline Tibia & 3 & 2 & 1,5 & 60 & 64,73 \\
\hline Astrágalo & 3 & 2 & 1,5 & 60 & 31,66 \\
\hline Calcáneo & 3 & 2 & 1,5 & 60 & 31,66 \\
\hline Metatarso & 3 & 2 & 1,5 & 60 & 29,93 \\
\hline 1a falange & 10 & 8 & 1,25 & 50 & 13,72 \\
\hline 2a falange & 11 & 8 & 1,3 & 52 & 13,72 \\
\hline 3 a falange & 10 & 8 & 1,25 & 50 & 13,72 \\
\hline
\end{tabular}

Tabla 3: Índices de aprovechamiento calculados sobre los restos identificados en la prospección de 2017 de Kangerlussuaq. Fuente: Elaboración propia.

${ }^{28}$ BINFORD, L. R. Nunamiut Ethnoarchaeology. Op. cit.; BINFORD, L. R. Bones... Op. cit. 

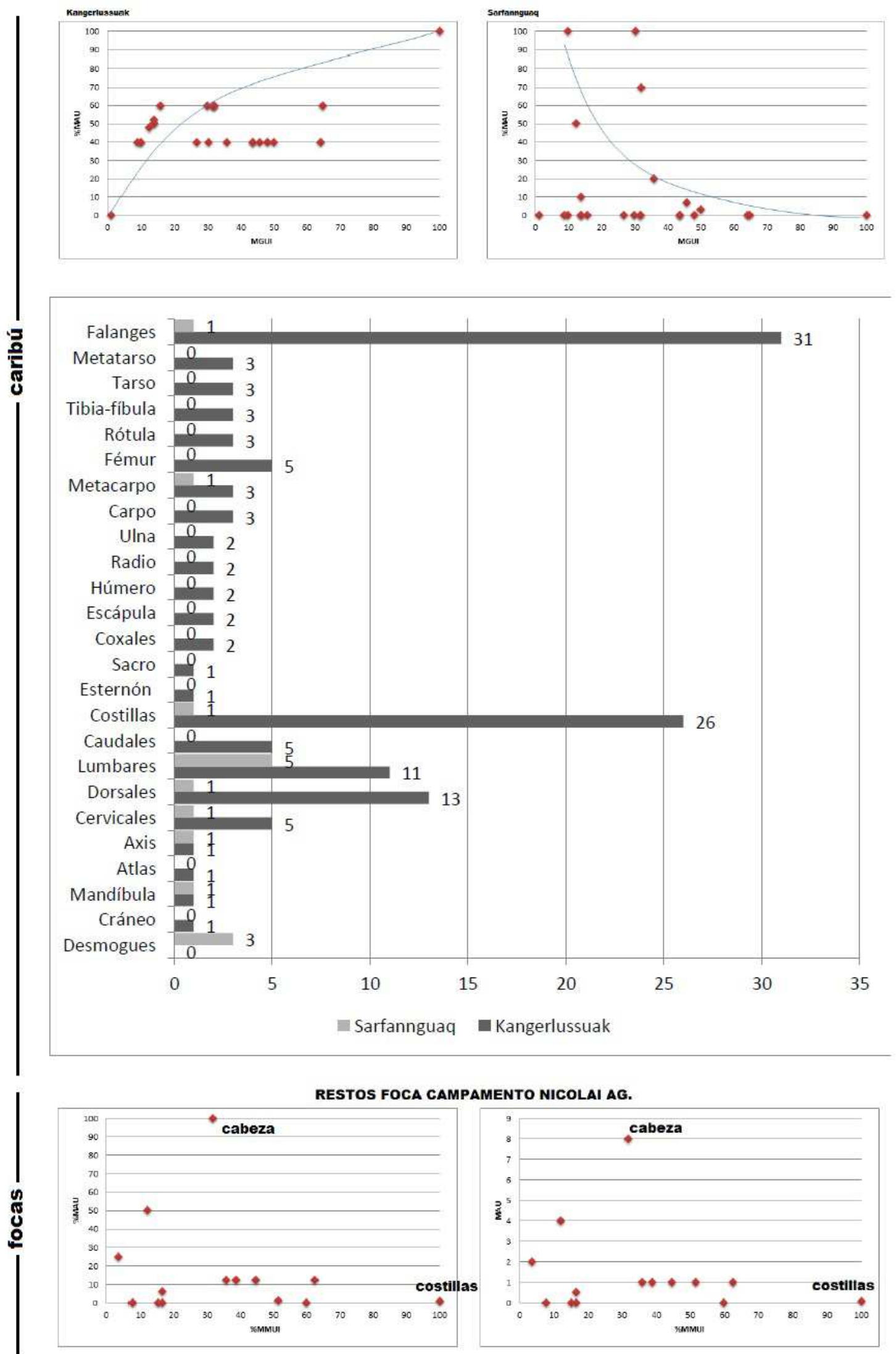

Fig. 10: Gráficas y tablas de índices de aprovechamiento. Fuente: Elaboración propia. 


\begin{tabular}{|l|c|c|c|c|c|}
\hline \multicolumn{6}{|c|}{ Zona de caza de Sarfannguak (kill site). Sólo caribú. } \\
\hline & Total & Frecuencia & MAU & \%MAU & MGUI \\
\hline Desmogues & 3 & 2 & 1,5 & - & 1,02 \\
\hline Cráneo & 0 & 1 & 0 & 0 & 8,74 \\
\hline Mandíbula & 1 & 1 & 1 & 100 & 30,26 \\
\hline Atlas & 0 & 1 & 0 & 0 & 9,79 \\
\hline Axis & 1 & 1 & 1 & 100 & 9,79 \\
\hline Cervicales & 1 & 5 & 0,2 & 20 & 35,71 \\
\hline Torácicas & 1 & 13 & 0,07 & 7 & 45,53 \\
\hline Lumbares & 5 & 7 & 0,7 & 70 & 32,05 \\
\hline Costillas & 1 & 26 & 0,03 & 3 & 49,77 \\
\hline Esternón & 0 & 1 & 0 & 0 & 64,13 \\
\hline Escápula & 0 & 2 & 0 & 0 & 43,47 \\
\hline Húmero & 0 & 2 & 0 & 0 & 43,47 \\
\hline Radio/ulna & 0 & 2 & 0 & 0 & 26,64 \\
\hline Carpales & 0 & 2 & 0 & 0 & 15,53 \\
\hline Metacarpo & 1 & 2 & 0,5 & 50 & 12,18 \\
\hline Pelvis & 0 & 1 & 0 & 0 & 47,89 \\
\hline Fémur & 0 & 2 & 0 & 0 & 100 \\
\hline Tibia & 0 & 2 & 0 & 0 & 64,73 \\
\hline Astrágalo & 0 & 2 & 0 & 0 & 31,66 \\
\hline Calcáneo & 0 & 2 & 0 & 0 & 31,66 \\
\hline Metatarso & 0 & 2 & 0 & 0 & 29,93 \\
\hline $1^{\text {a }}$ falange & 0 & 8 & 0 & 0 & 13,72 \\
\hline $2^{\text {a }}$ falange & 1 & 8 & 0,1 & 10 & 13,72 \\
\hline $3^{\text {a }}$ falange & 0 & 8 & 0 & 0 & 13,72 \\
\hline
\end{tabular}

Tabla 4: Índices de aprovechamiento calculados sobre los restos identificados en la prospección de 2017 de Sarfannguak. Fuente: Elaboración propia.

En Sisimiut-Sarfannguaq se recabaron datos etnoarqueológicos más útiles sobre la caza de animales marinos y terrestres y la pesca tradicional y moderna del bacalao, prospectándose además un cazadero tradicional y el propio pueblo, analizando pormenorizadamente el registro óseo presente en ambos. En dicho contexto se estudiaron también estructuras arqueológicas y etnográficas, tales como inuksuit, tumbas antiguas thule y escondrijos de carne, lo mismo que en Asummiut. Los informantes proporcionaron testimonios y acciones de supervivencia de caza y pesca tradicional como hábitos actuales.

Valorados en su conjunto, se documentó así la cadena operativa completa de procesado del caribú mediante una colección de ejemplos de decenas de individuos, desde su caza hasta su consumo, comparable con las de Kapisillit, Atammik y Nuuk.

Pese a la cercanía relativa del área de Sisimiut-Sarfannguaq con Atammik, Nuuk y Kapisillit y las semejanzas evidentes, se han detectado gestos, técnicas y hábitos de consumo distintos, lo que se explica por la ya mencionada exclusividad de las cadenas operativas, incluso entre poblaciones inmediatas ${ }^{29}$. Hemos documentado 
otra forma diferente a las ya conocidas de primera carnicería en el punto de la muerte, y otra forma de transportar los cuartos delanteros y los traseros, distinguiéndose también los paquetes concebidos por los carniceros y generados para su almacenamiento, secado y reparto. Para advertir las diferencias e identificar los pormenores de la cadena operativa, son necesarios tanto la representación anatómica como su distribución espacial, y también las marcas antrópicas o animales/climáticas estudiadas en su conjunto e interrelacionadas y no por separado; análisis de múltiples variables que recomiendan ciertos especialistas ${ }^{30}$.

Por lo mencionado, la principal reflexión de este trabajo de etnoarqueología desaconseja la extrapolación directa de una secuencia operativa de procesado animal, obtenida entre un subgrupo inuit, para interpretar el registro arqueológico o etnográfico de todo el Ártico americano o para otras regiones de bosque frío asiático o europeo actual y prehistórico, como sin embargo se ha venido haciendo con el clásico compendio Nunammiut descrito por Binford ${ }^{31}$, en el que incluso se ha pretendido la extensión a cualquiera de las comunidades cazadoras-recolectoras del mundo en el presente y en el pasado. Los inuit son genéricamente "Gentes del Ártico" y su contexto cultural abarca desde Rusia a Alaska, Canadá y Groenlandia32, pero existen decenas de subgrupos con una esencia cultural común y unas tradiciones análogas pero con una notoria y lógica variabilidad en usos concretos. Las cadenas de procesado de diferentes animales son una de esas dimensiones en la que las costumbres difieren. Spiess ${ }^{33}$ ya advirtió con menos detalle diferencias en el procesado del caribú entre múltiples grupos y matizamos que éstas se dan incluso entre cazadores de poblaciones inmediatas ${ }^{34}$; ahora se aporta otro contexto en el que se distinguen más diferencias: el área de Sisimiut.

Asumiendo la gran variabilidad del comportamiento cazador-recolector en lo que a secuencias de carnicería se refiere y a que no existe un mismo proceso técnico común, éste y otros ejemplos etnoarqueológicos tienen, en cambio, otra potencial utilidad para afrontar la difícil tarea de interpretar adecuadamente el registro zooarqueológico. Es el punto de encuentro, la esencia común en el ámbito de estudio del procesado animal -y en cualquier otro-, entre cualquier grupo o subgrupo inuit y de éstos con cualquier comunidad de cazadores-recolectores de características análogas, independientemente del contexto geográfico al que pertenezcan. Cualquiera de las cadenas de acciones relativas a la caza y al procesado, consumo y descarte de las presas ha de ser coherente con la estructura de racionalidad tradicional que acotaría la panoplia de elecciones posibles en los

\footnotetext{
30 GIFFORD-GONZÁLEZ, D. Bones are not enough: Analogues, Knowledge, and Interpretive Strategies in Zooarchaeology. Journal of Anthropological Archaeology. 1991, n. 10, pp. 215-254; DOMíNGUEZ-RODRIGO, M. The Study of Skeletal Part Profiles: an Ambiguous Taphonomic Tool for Zooarchaeology. Complutum. 1999, n. 10, pp. 15-24.

YRAVEDRA SAINZ DE LOS TERREROS, J. Tafonomía aplicada... Op. cit.

${ }^{31}$ BINFORD, L. R. Nunamiut Ethnoarchaeology. Op. cit.

${ }^{32}$ BAILÓN, F. Los poetas del Ártico. Historias de Groenlandia. Sevilla: Guadalturia, 2012; BAILÓN, F. Los Inuit: Cazadores del Gran Norte. Barcelona: Nova Cosa Editorial, 2015.

${ }^{33}$ SPIESS, A. E. Reindeer and Caribou Hunters. An Archaeological Study. Nueva York: Academic Press, 1979

${ }^{34}$ DOMÍNGUEZ-SOLERA, S. D. Estudio etnoarqueológico. Op. cit.
} 
procesos técnicos ${ }^{35} \mathrm{y}$ aporta lógica al comportamiento cultural diverso.

La clave radica en la particular relación simbólica entre seres humanos y animales de cualquier comunidad de cazadores-recolectores de religión animista, ontología que se basa en la atribución potencial de alma (inua en el caso de los inuit) y personalidad humana a todos los seres y objetos conocidos ${ }^{36}$. La cultura inuit reconocía, además, chamanes especialistas (angakok ${ }^{37}$ ), cuya función principal era la de la dirigir la correcta interrelación simbólica entre los seres humanos con los otros seres animados, de acuerdo con las normas comunes preestablecidas. Y es que la cultura inuit tradicional, al igual que la de otros grupos de creencias animistas, no reconoce una diferencia dicotómica entre "natural" y "humano" dentro de su respectiva forma de percibir tiempo y espacio ${ }^{38}$. De este modo, desde una perspectiva animista, se categoriza al ser humano siempre en condición de completa igualdad con respecto al resto de animales, a los que se considera explícitamente "gente" y se les atribuye por tipos una personalidad antropizada. Existirían una serie de normas ancestrales y reconocidas por todos los miembros de la comunidad que dictan la correcta relación mutua entre todas las criaturas. En lo tocante al ámbito de la caza y el procesado del animal, dichas reglas estrictas indican qué animales se comen, qué partes son más adecuadas para comer o para elaborar ropas 0 instrumentos y cuáles son nocivas, pero también cuándo y cómo se cazan y se procesan, cómo y dónde se descartan, etc.

En el caso inuit y dentro de la anterior estructura de racionalidad, existen clasificaciones taxonómicas y atribuciones simbólicas, y la principal sería la que distingue entre los animales de tierra y de mar. Común a todos los grupos es, por ejemplo, el mito de Sedna, ser sobrenatural de la que surgirían todas las criaturas marinas $^{39}$. En cualquiera de las tradiciones de los grupos inuit de todo el Ártico, los animales terrestres no pueden cazarse juntos, no pueden comerse mezclados con los marinos y tampoco pueden combinarse sus pieles; $y$ a sus huesos suele dárseles un tratamiento diferenciado ${ }^{40}$. También hay animales caracterizados como "de

35 LEMONNIER, P. The Study of Material Culture Today: toward an Anthropology of Technical Systems. Journal of Anthropological Archaeology. 1986, vol. 5, n. 2, pp. 147-186.

${ }_{36}$ DESCOLA, P. Las cosmologías indígenas de la Amazonia. En: SURRALLÉS, A. y GARCíA HIERRO, P. (eds.). Tierra adentro. Territorio indígena y percepción del entorno. Copenhague: IWGIA, 2004, pp. 25-35; VIVEIROS DE CASTRO, E. Perspectivismo y Multinaturalismo en la América Indígena. En: SURRALLÉS, A. y GARCÍA HIERRO, P. (eds.). Tierra adentro. Territorio indígena y percepción del entorno. Copenhague: IWGIA, 2004, pp. 37-80.

${ }_{37}$ MORAL-GARCÍA, C. Acercamiento a la ontología y cosmología inuit tradicional: de los "inue" al "angakoq". Naveg@mérica, Revista electrónica editada por la Asociación Española de Americanistas. 2017, n. 18.

${ }_{38}$ INGOLD, T. Hunting and Gathering as Ways of Perceiving the Environment. En: ELLEN, R. y FUKUI, K. (eds.). Redefining Nature: Ecology, Culture and Domestication. Oxford: Oxford International Publisher Ltd, 1996, pp. 117-155; HERNANDO, A. Arqueología de la Identidad. Madrid: Akal, 2002; LAUGRAND, F. y OOSTEN, J. Hunters, Predators and Prey: Inuit perceptions of animals. Nueva York: Berghahn Books, 2015.

${ }_{39}$ LAUGRAND, F. y OOSTEN, J. The Sea Woman: Sedna in Inuit Shamanism and Art in the Eastern Arctic. Fairbanks: University of Alaska Press, 2008.

40 MAUSS, M.; DURKHEIM, É. y BEUCHAT, H. Ensayo sobre las variaciones estacionales en las sociedades esquimales: un estudio de morfología social. En: MAUSS, M. (ed.). Sociología y Antropología. Madrid: Technos, 1972 [1904-1905], pp. 408-409; FORDE, C. D. Los esquimales: cazadores de focas y caribús en la América Ártica. En: Hábitat, Economía y Sociedad. Introducción a 
invierno" y otros como "de verano", con una serie de tabúes al respecto (ibídem). Todo esto está contenido y se hace legible en los mitos, el vehículo de explicación y transmisión oral de todo el conocimiento que conforma el corpus de esta cultura o de cualquier otra similar ${ }^{41}$.

Pese a las décadas de cristianización, occidentalización y capitalización que han incido sobre la cultura tradicional de Groenlandia, que ha borrado de la memoria muchas de las prácticas heredadas del pasado tradicional, caza y pesca siguen siendo las actividades fundamentales para la subsistencia de las familias de los poblados pequeños, y los dos principales pilares de la identidad. El aprendizaje de la caza, el de procesar y consumir de forma adecuada las presas, pero también los gustos y otras cuestiones con mayor o menor relación con este ámbito (en el sentido de la adquisición del habitus ${ }^{42}$ ) siguen haciéndose por transmisión directa de padres y madres a hijos e hijas. Es por ello por lo que existen, se mantienen y perpetúan las susodichas "tradiciones técnicas", distintas entre poblaciones. Pero también influye esta forma de transmisión directa y oral en la pervivencia de gestos y usos que, aunque ya casi descargados de su contenido simbólico original, siguen influyendo en el resultado de la cadena operativa. Es sobre todo destacable cómo los cazadores de Sisimiut -como lo hacen también los de Kapisillit y Atammik ${ }^{43}$ - suelen arrojar los restos descartados de los animales marinos al mar y los terrestres a la tierra (con la excepción de si las labores de procesado que se desarrollan en un barco). Incluso los metápodos y falanges de caribú que se seccionan en los puertos, no se arrojan al agua sino que se apartan a un lado del embarcadero. Contextos de deposición faunística exclusiva de animales acuáticos, como el del campamento de Nikolai Agustusen, son al mismo tiempo huella elocuente y esconden la anterior justificación más profunda. Todos los gestos de carnicería y descarte han de realizarse adecuadamente, no sólo porque se consideren más eficientes técnicamente o como la "mejor manera de hacer las cosas", sino porque también significan gestos de respeto merecidos por los animales, hecho que, sin excepción, se esforzaron en intentar transmitirnos todos los informantes.

El tratamiento diferencial de las cabezas del caribú también ha de entenderse en esta dirección ${ }^{44}$. La exhibición de cabezas de grandes presas no derivaría (al menos en exclusiva, pudiendo ser una costumbre concurrente) de la influencia de cazadores occidentales como trofeos deportivos ${ }^{45}$, sino que en la tradición inuit tienen un profundo sentido simbólico como receptáculo del alma -inua- de esos animales $^{46}$ y merecen mayor consideración que las de hembras y machos pequeños

la Etnología. Barcelona: Oikos-Tau, 1995, p. 133.

${ }^{41}$ ONG, W. Oralidad y escritura. Tecnologías de la palabra. México: Fondo de Cultura Económica, 1987; Hernando, A. Arqueología... Op. cit.

${ }^{42}$ BORDIEU, P. El sentido práctico. Madrid: Taurus, 1991.

${ }^{43}$ DOMÍNGUEZ-SOLERA, S. D. Estudio etnoarqueológico. Op. cit.

${ }^{44}$ Ibídem.

${ }^{45}$ DOMÍNGUEZ-SOLERA, S. D. Rituales de paso... Op. cit.

${ }^{46}$ AUGER, E. E. The Way of Inuit Art. Londres: McFarland \& Company, 2005, p. 92; ROSING, C. Østgrønlænderne: Tunuamiut. Grønlands Sidste Hedninger. Det grønlandske Selskabs Skrifter. Copenhague, 1946 [1906]. Cit. por: GULLØW, H. C. The End of the Thule Culture and the Rise of the Native Thoughts - Ammassalik, a Key to another World. En: GRØNNOW, B. (ed.). On the Track of the 
que, aunque con respeto, son elocuentemente abandonadas en el punto de la muerte.

La presa se almacena dividida en las mencionadas partes, que también son las concebidas para el reparto entre los miembros del grupo. Como en cualquier sociedad cazadora-recolectora presente o pasada $^{47}$, para la cultura inuit, el reparto de la presa entre los participantes en la expedición de caza y después entre los familiares y allegados, está estrictamente reglada. El cazador principal, el que disparó al animal, está obligado a repartirlo entre los otros acompañantes según el papel que éstos hubiesen tenido en el lance cinegético. Las partes que cada cual recibe no son necesariamente las que tienen más contenido cárnico o graso (sensu la Economic Anatomy de Binford ${ }^{48}$ ), sino que se valoran según una consideración cultural subjetiva (sensu Lemonnier ${ }^{49}$ ) repartiendo, no para recibir después, sino por su concepto de solidaridad generalizada y por cumplir con el deber convencionalizado ${ }^{50}$. En Groenlandia, como en cualquier otra parte del Ártico, cada zona y cada animal tenía sus respectivas normas de reparto ${ }^{51}$, preceptos que hoy se van diluyendo y modificando aunque siga siendo inconcebible el hecho de no repartir lo cazado entre familiares, compañeros y otros allegados. En el pasado y en coherencia con las creencias animistas ${ }^{52}$ que estructuran el pensamiento inuit tradicional, el reparto adecuado sería otro de los gestos de respeto hacia la generosidad de la presa que se dejaba cazar ${ }^{53}$.

También existen en esta parte de Groenlandia convencionalismos para el adecuado reparto y consumo de las focas dentro de preceptos socioculturales de tipo simbólico ${ }^{54}$ que condicionan la carnicería y el transporte. Sí existen cálculos sobre índices de aprovechamiento para focas ${ }^{55}$, ya que los índices de utilidad para los mamíferos terrestres no se adecúan a la morfología específica de éstas. Si sometemos a dicho estudio la acción de procesado y la colección documentada en el campamento de Nikolai Agustusen (al registro preexistente se suman los descartes del procesado de la foca que cazó y descuartizó allí), empleando los

Thule Culture from Bering Strait to East Greenland. Copenhague: Publications of the National Museum, 2009, pp. 245-255.

47 WAGUESPACK, N. M. Caribou Sharing and Storage: Refitting the Palangana Site. Journal of Anthropological Archaeology. 2002, n. 21, pp. 396-417; SAHLINS, M. Stone Age Economics. Chicago: Aldine, 1972.

${ }^{48}$ BINFORD, L. R. Nunamiut Ethnoarchaeology. Op. cit.

${ }^{49}$ LEMONNIER, P. The Study... Op. cit.

${ }^{50}$ GOWDY, J. Hunter-gatherers and the Mythology of the Market. En: LEE, R. y DALY, R. (eds.). The Cambridge Encyclopedia of Hunters and Gatherers. Cambridge: Cambridge University Press, 1999, pp. 391-398.

${ }^{51}$ LÉVESQUE, C. [et al.]. Between Abundance and Scarcity: Food and the Institution of Sharing among the Inuit of the Circumpolar Region during the Recent Historical Period. En: Duhaime, G. (ed.). Sustainable Food Security in the Arctic: State of Knowledge. Edmonton: CCI Press, 2002, pp. 103115.

${ }^{52}$ DESCOLA, P. Las cosmologías... Op. cit.

${ }^{53}$ LÉVESQUE, C. [et al.]. Between Abundance... Op. cit., p. 108.

${ }^{54}$ ROBBE, P. Partage du gibier chez les Ammassalimiut observé en 1972, dans le village de Tîleqilaq. Objets et Mondes. 1975, vol. 15, n. 2, pp. 209-222; SANDELL, H. T. Archaeology and Environment... Op. cit.; HANSEN, K. Nuussuarmiut... Op. cit.

${ }_{55}$ LYMAN R. L.; SAVELLE, J. M. y WHITRIDGE, P. Derivation and Application of a Meat Utility Index for Phocid Seals. Journal of Archaeological Science. 1992, vol. 19, n. 5, pp. 531-555. 
valores para focas en general (Fig. 10, Tabla 5), se confirma el transporte de las partes más ricas en grasa y carne: los costillares, la parte de la pelvis con las patas traseras y las zona de las vértebras. También se observa que algunas de las partes aptas para el consumo se consumirían allí, tales como costillares y partes de las vértebras. Comparando las gráficas de MAU-\%MMUI y \%MAU-\%MMUI con las calculadas siguiendo los mismos criterios y consignadas en Lyman et al. ${ }^{56}$, coinciden con las confeccionadas sobre la base de los resultados de campamentos arqueológicos costeros desde época Thule en el este de Canadá.

\begin{tabular}{|l|c|c|c|c|c|}
\hline \multicolumn{7}{|c|}{ Nikolai Agustusen (campamento). Focas. } \\
\hline & Total NME & Frecuencia & MAU & $\%$ MAU & MMUI \\
\hline Cráneo (con mandíbula) & 8 & 1 & 8 & 100 & 31,6 \\
\hline Cervicales & 7 & 7 & 1 & 12,5 & 35,8 \\
\hline Torácicas & 13 & 13 & 1 & 12,5 & 62,4 \\
\hline Lumbares & 7 & 7 & 1 & 12,5 & 38,7 \\
\hline Pelvis & 1 & 1 & 1 & 12,5 & 44,5 \\
\hline Costillas & 2 & 26 & 0,07 & 0,87 & 100 \\
\hline Esternón & 1 & 1 & 1 & 1,25 & 51,4 \\
\hline Escápula & 0 & 2 & 0 & 0 & 59,9 \\
\hline Húmero & 0 & 2 & 0 & 0 & 15,2 \\
\hline Radio/ulna & 0 & 2 & 0 & 0 & 7,7 \\
\hline Aleta delantera & 84 & 42 & 2 & 25 & 3,6 \\
\hline Fémur & 1 & 2 & 0,5 & 6,25 & 16,5 \\
\hline Tibia & 0 & 2 & 0 & 0 & 16,5 \\
\hline Aleta trasera & 168 & 42 & 4 & 50 & 12,1 \\
\hline
\end{tabular}

Tabla 5: Índices de aprovechamiento calculados sobre los restos de foca identificados en el Campamento de N. Agustusen en 2017. Fuente: Elaboración propia.

Es también elocuente el hecho de que a los perros no se los alimente con las partes marginales, sino que se consideren las porciones más adecuadas para ello los cuartos traseros, los segundos en la lista de índices de aprovechamiento ideales ${ }^{57}$. También hay que precisar que en las carnicerías y las casas, antes del cocinado/consumo se subdividen todos los elementos. Una variante serían ejemplos más puntuales de aletas traseras que no se descartarían como en la secuencia más común antedicha y que serían transportadas tanto para el consumo humano como para la entrega a los perros, sin retirarles la piel.

Por último, hay que subrayar que la inexistencia de un patrón de procesado único entre todas las comunidades de cazadores-recolectores actuales hace imposible desarrollar analogías universalistas del tipo de las Teorías de Alcance Medio (según el sentido de Binford ${ }^{58}$ ), tal y como ya advirtiera Yellen ${ }^{59}$, por lo que cada cadena operativa de procesado de cierto taxón animal documentada en

\footnotetext{
${ }^{56}$ Ibídem.

${ }^{57}$ Ibídem.

${ }^{58}$ BINFORD, L. R. Nunamiut Ethnoarchaeology. Op. cit.; BINFORD, L. R. Bones... Op. cit.

59 YELLEN, J. E. Cultural Pattering in Faunal Remains: Evidence from the Kung Busmen. En: INGERSOLL, D.; YELLEN, J. E. y MCDONALD, W. (eds.). Experimental Archaeology. Nueva York: Columbia University Press, 1977, pp. 271-331; YELLEN, J. E. Archaeological Approaches to the Present. Models for Reconstructing the Past. Nueva York: Academic Press, 1977.
} 
determinado registro arqueológico ha de estudiarse como única y propia de la comunidad que lo generó. Aunque sí existe la misma estructura de cadena operativa en la que se ordenan las diferentes acciones y la operatividad de una misma lógica que las motiva ${ }^{60}$ y este nuevo compendio de cadenas operativas documentado en el área de Sisimiut vuelve a revalidar la idea de que todas las distintas etapas de la secuencia de caza y procesado animal, ya sea la carnicería el consumo, el reparto o el descarte, se solapan entre ellas ${ }^{61}$. Pero, sobre todo, este ensayo aporta más pruebas a la idea de que las cuestiones culturales y simbólicas influyen decisivamente en el resultado del procesado animal ${ }^{62}$, que hay que estudiarlas, ya que sus resultados se hacen materiales $y$, por lo tanto, son legibles zooarqueológicamente, además de intentar comprender las razones extrasomáticas derivadas de cuestiones ecológicas y prácticas, aunque resulte imposible recuperar el contenido narrativo concreto que las motivaron.

En definitiva, los resultados de la campaña de 2017 han servido para alcanzar los objetivos de investigación propuestos, reforzando con nuevos y más precisos datos las interpretaciones obtenidas en trabajos anteriores y profundizando más en su alcance como instrumentos para interpretar el registro arqueológico. También muestran el potencial que aún se conserva en el oeste de Groenlandia para desarrollar estudios etnoarqueológicos de este tipo, valor que inexorablemente se irá perdiendo cada vez más diluido a causa del rápido avance de la occidentalización entre los pueblos del Ártico.

\section{Bibliografía}

AUGER, E. E. The Way of Inuit Art. Londres: McFarland \& Company, 2005.

BAILÓN, F. Los poetas del Ártico. Historias de Groenlandia. Sevilla: Guadalturia, 2012.

BAILÓN, F. Los Inuit: Cazadores del Gran Norte. Barcelona: Nova Cosa Editorial, 2015.

BINFORD, L. R. Nunamiut Ethnoarchaeology. Nueva York: Academic Press, 1978.

BINFORD, L. R. Bones: Ancient Men and Modern Myths. Nueva York: Academic Press, 1981.

BORDIEU, P. El sentido práctico. Madrid: Taurus, 1991.

DESCOLA, P. Las cosmologías indígenas de la Amazonia. En: SURRALLÉS, A. y GARCÍA HIERRO, P. (eds.). Tierra adentro. Territorio indígena y percepción del entorno. Copenhague: IWGIA, 2004, pp. 25-35.

\footnotetext{
${ }^{60}$ DOMÍNGUEZ-SOLERA, S. D. Estudio etnoarqueológico. Op. cit.

${ }^{61}$ lbídem.

62 POLITIS, G. y SAUNDERS, N. J. Archaeologícal Correlates of Ideological Activity: Food Taboos and the Spirit Animal in an Amazonian Hunter-gatherer Society. En: MIRACLE, P. y MILNER, N. (eds.). Consuming Passions and Patterns of Consumption. Cambridge: McDonald Institute for Archaeological Research; University of Cambridge, 2002, pp. 113-130.
} 
DOMíNGUEZ-RODRIGO, M. The Study of Skeletal Part Profiles: an Ambiguous Taphonomic Tool for Zooarchaeology. Complutum. 1999, n. 10, pp. 15-24.

DOMÍNGUEZ-SOLERA, S. D. Rituales de paso de los cazadores españoles actuales (Estudio etnoarqueológico). Arqueoweb. Revista sobre Arqueología en Internet. 2008, vol. 9, n. 2.

DOMíNGUEZ-SOLERA, S. D. With only one Flake. An Experiment about the Posibilities Processing a Carcass with Flint during Hunting. Journal of Taphonomy. 2012, vol. 10, n. 2, pp. 113-121.

DOMÍNGUEZ-SOLERA, S. D. Inuksuit en el oeste de Groenlandia: símbolo y huella de la relación ancestral de los inuit con el espacio. Revista Española de Antropología Americana. 2014, vol. 44, n. 1, pp. 151-166.

DOMíNGUEZ-SOLERA, S. D. Los Inuit. Caza y pesca en el Oeste de Groenlandia. Cuaderno de Campo. Madrid: Libros Clan, 2014.

DOMÍNGUEZ-SOLERA, S. D. Etnoarqueología y el mar en el Oeste de Groenlandia: varios apuntes útiles sobre la pesca del bacalao. En: HOCES-GARCÍA, A. y MORAL-GARCÍA, C. (coords.). El mar: una forma de vida en América. Madrid: Historia y Cultura del Mar, 2016, pp. 243-272.

DOMÍNGUEZ-SOLERA, S. D. Estudio etnoarqueológico: cadenas operativas de caza y procesado animal entre grupos cazadores-recolectores [tesis doctoral]. Madrid: Universidad Complutense de Madrid, 2017.

DOMÍNGUEZ-SOLERA, S. D. Por tierra y por mar: reflexiones sobre la caza en el Oeste de Groenlandia. Naveg@mérica, Revista electrónica editada por la Asociación Española de Americanistas. 2017, n. 18.

DOMíNGUEZ-SOLERA, S. D. Man the Gatherer: Los Ju/'hoansi de la Nyae Nyae (Namibia) y la actividad recolectora masculina durante las expediciones de caza. En: DOMíNGUEZ-SOLERA, S. D. (coord.). Etnoarqueología Total: Para todas las épocas, para todas las sociedades, para todos los temas. Vol. 1. Cuenca: UIMP; Diputación de Cuenca, 2018, pp. 19-29.

DOMÍNGUEZ-SOLERA, S. D. y DOMÍNGUEZ-RODRIGO, M. A Taphonomic Study of a Carcass Consumed by Griffon Vultures (Gyps fulvus) and its Relevance for the Interpretation of Bone Surface Modifications. Journal of Archaeological and Anthropological Scieces. 2011, vol. 3, n. 4, pp. 385-392.

ESTIOKO-GRIFFIN, A. y GRIFFIN, P. B. Woman the Hunter: The Agta. En: DAHLBERG, F. (ed.). Woman the Gatherer. New Haven: Yale University Press, 1981, pp. 121-151. 
FORDE, C. D. Los esquimales: cazadores de focas y caribús en la América Ártica. En: Hábitat, Economía y Sociedad. Introducción a la Etnología. Barcelona: Oikos-Tau, 1995, pp. 125-147.

GONZÁLEZ-RUIBAL, A. La experiencia del otro. Una introducción a la Etnoarqueoligía. Madrid: Akal, 2003.

GIFFORD-GONZÁLEZ, D. Bones are not enough: Analogues, Knowledge, and Interpretive Strategies in Zooarchaeology. Journal of Anthropological Archaeology. 1991, n. 10, pp. 215-254.

GOWDY, J. Hunter-gatherers and the Mythology of the Market. En: LEE, R. y DALY, R. (eds.). The Cambridge Encyclopedia of Hunters and Gatherers. Cambridge: Cambridge University Press, 1999, pp. 391-398.

GRØNNOW, B.; MELDGAARD, M. y NIELSEN, J. B. Aasivissuit - The Great Summer Camp. Archaeological, Ethnographical and Zoo-archaeological Studies of a Caribou-hunting Site in West Greenland. Meddelelser om Grønland. Copenhague: Danish Polar Center, 1983.

GULLøW, H. C. The End of the Thule Culture and the Rise of the Native Thoughts Ammassalik, a Key to another World. En: GRØNNOW, B. (ed.). On the Track of the Thule Culture from Bering Strait to East Greenland. Copenhague: Publications of the National Museum, 2009, pp. 245-255.

HALLENDY, N. Inuksuit: Semalithic Figures Constructed in the Canadian Arctic. $25^{\text {th }}$ Annual Meeting of the Canadian Archaeological Association. Ontario, 1992.

HALLENDY, N. The Silent Mesengers. Equinox. 1997, n. 85, pp. 36-46.

HANSEN, K. Jigs from Greenland. En: GILBERG, R. y GULLøW, H. C. (eds.). Fifty Years of Arctic Research. Anthropological Studies from Greenland to Siberia. Copenhague: National Museum of Denmark, 1997, pp. 149-156.

HANSEN, K. Nuussuarmiut- Hunting Families on the Big Headland. Copenhague: The Commission for Scientific Research in Greenland, 2008.

HERNANDO, A. Arqueología de la Identidad. Madrid: Akal, 2002.

INGOLD, T. Hunting and Gathering as Ways of Perceiving the Environment. En: ELLEN, R. y FUKUI, K. (eds.). Redefining Nature: Ecology, Culture and Domestication. Oxford: Oxford International Publisher Ltd, 1996, pp. 117-155.

LAUGRAND, F. y OOSTEN, J. The Sea Woman: Sedna in Inuit Shamanism and Art in the Eastern Arctic. Fairbanks: University of Alaska Press, 2008.

LAUGRAND, F. y OOSTEN, J. Hunters, Predators and Prey: Inuit perceptions of animals. Nueva York: Berghahn Books, 2015. 
LEMONNIER, P. The Study of Material Culture Today: toward an Anthropology of Technical Systems. Journal of Anthropological Archaeology. 1986, vol. 5, n. 2, pp. 147-186.

LÉVESQUE, C. [et al.]. Between Abundance and Scarcity: Food and the Institution of Sharing among the Inuit of the Circumpolar Region during the Recent Historical Period. En: Duhaime, G. (ed.). Sustainable Food Security in the Arctic: State of Knowledge. Edmonton: CCI Press, 2002, pp. 103-115.

LYMAN R. L.; SAVELLE, J. M. y WHITRIDGE, P. Derivation and Application of a Meat Utility Index for Phocid Seals. Journal of Archaeological Science. 1992, vol. 19 , n. 5, pp. 531-555.

MAUSS, M.; DURKHEIM, É. y BEUCHAT, H. Ensayo sobre las variaciones estacionales en las sociedades esquimales: un estudio de morfología social. En: MAUSS, M. (ed.). Sociología y Antropología. Madrid: Technos, 1972 [19041905], pp. 359- 432.

MORAL-GARCÍA, C. Acercamiento a la ontología y cosmología inuit tradicional: de los "inue" al "angakoq". Naveg@mérica, Revista electrónica editada por la Asociación Española de Americanistas. 2017, n. 18.

MØBJERG, T. y GRUMMESGAARD-NIELSEN, S. Saqqaq-Kulturen på Asummiut. Tidsskriftet Gronland. 1997, n. 5-7, pp. 239-259.

ONG, W. Oralidad y escritura. Tecnologías de la palabra. México: Fondo de Cultura Económica, 1987.

PASDA, K. Zur Taphonomie von Rentieren (Rangifer tarandus grienlandicus) in der Tundra Westgrönlands. Quartär. 2001, n. 51/52, pp. 173-194.

POLITIS, G. y SAUNDERS, N. J. Archaeologícal Correlates of Ideological Activity: Food Taboos and the Spirit Animal in an Amazonian Hunter-gatherer Society. En: MIRACLE, P. y MILNER, N. (eds.). Consuming Passions and Patterns of Consumption. Cambridge: McDonald Institute for Archaeological Research; University of Cambridge, 2002, pp. 113-130.

ROBBE, P. Partage du gibier chez les Ammassalimiut observé en 1972, dans le village de Tîleqilaq. Objets et Mondes. 1975, vol. 15, n. 2, pp. 209-222.

ROSING, C. Østgrønlænderne: Tunuamiut. Grønlands Sidste Hedninger. Det grønlandske Selskabs Skrifter. Copenhague, 1946 [1906].

SAHLINS, M. Stone Age Economics. Chicago: Aldine, 1972.

SANDELL, H. T. Archaeology and Environment in the Scaresby Sund Fjord. Ethnoarchaeological Investigations of the Last Thule Culture of Notheast Greenland. 
Meddelelser om Grønland, Man and Society. Copenhague: Danish Polar Center, 1991.

SPIESS, A. E. Reindeer and Caribou Hunters. An Archaeological Study. Nueva York: Academic Press, 1979.

VIVEIROS DE CASTRO, E. Perspectivismo y Multinaturalismo en la América Indígena. En: SURRALLÉS, A. y GARCÍA HIERRO, P. (eds.). Tierra adentro. Territorio indígena y percepción del entorno. Copenhague: IWGIA, 2004, pp. 3780.

VV.AA. The Inuit Way. A Guide to Inuit Culture. Nunavut: Pauktuutit Inuit Women of Canada, 2006.

WAGUESPACK, N. M. Caribou Sharing and Storage: Refitting the Palangana Site. Journal of Anthropological Archaeology. 2002, n. 21, pp. 396-417.

WOOD, W. R. y Johnson, D. L. A Survey of Disturbance Processes in Archaeological Site Formation. Advances in Archaeological Method and Theory. Nueva York: Academic Press, 1978, pp. 315-380.

YELLEN, J. E. Archaeological Approaches to the Present. Models for Reconstructing the Past. Nueva York: Academic Press, 1977.

YELLEN, J. E. Cultural Pattering in Faunal Remains: Evidence from the Kung Busmen. En: INGERSOLL, D.; YELLEN, J. E. y MCDONALD, W. (eds.). Experimental Archaeology. Nueva York: Columbia University Press, 1977, pp. 271-331.

YRAVEDRA SAINZ DE LOS TERREROS, J. Tafonomía aplicada a Zooarqueología. Madrid: Universidad Nacional de Educación a Distancia, 2006. 